\title{
Observed changes in dry day frequency and prolonged dry episodes in Northeast China
}

\author{
Xiaodong Liu, ${ }^{\mathrm{a}}$ Binhui Liu, ${ }^{\mathrm{b} *}$ Mark Henderson, ${ }^{\mathrm{c}}$ Ming $\mathrm{Xu}^{\mathrm{d}, \mathrm{e}}$ and Daowei Zhou ${ }^{\mathrm{f}}$ \\ ${ }^{a}$ Key Laboratory for Silviculture and Conservation, Beijing Forestry University, China \\ ${ }^{\mathrm{b}}$ College of Forestry, The Northeast Forestry University, Harbin, China \\ c Public Policy and Environmental Studies Programs, Mills College, Oakland, CA, USA \\ d Institute of Geographical Sciences and Natural Resources Research, Chinese Academy of Sciences, Beijing, China \\ e Center for Remote Sensing and Spatial Analysis, Department of Ecology, Evolution and Natural Resources, Rutgers University, \\ New Brunswick, NJ, USA \\ ${ }^{\mathrm{f}}$ Northeast Institute of Geography and Agroecology, Chinese Academy of Sciences, Changchun, China
}

\begin{abstract}
Daily precipitation data from 34 weather stations in Northeast China from 1960 to 2008 are used to examine trends in the occurrence of dry days and prolonged dry episodes. Trends in the mean length and frequency of prolonged dry episodes, as well as the number of dry days within prolonged dry episodes (DDPDE), are computed regionally and for individual stations at the threshold levels of 1 and $2 \mathrm{~mm} \mathrm{day}^{-1}$. Regionally, the number of dry days is increasing in the summer half-year and decreasing in the winter half-year. DDPDE is significantly increasing in the summer half-year; the increased frequency of dry spells has the greatest effect. The mean length of prolonged dry episodes in the winter half-year has decreased significantly. Our results indicate that neither the frequency nor the mean length of prolonged dry episodes, alone, can adequately describe the short-term dry conditions of an area. Multiple characteristics of dry spells, including frequency, length, and the number of DDPDE should be considered. DDPDE is a function of both the frequency and length of dry episodes, but may be more influenced by one or the other characteristics of dry spells, depending on the season or region.
\end{abstract}

KEY WORDS dry day; prolonged dry episode; precipitation; trend analysis; climate change; Northeast China

Received 13 January 2013; Revised 1 February 2014; Accepted 5 February 2014

\section{Introduction}

This study is concerned with the trends and variability in the frequency of dry days and prolonged dry episodes in China's northeastern region. Although there are a variety of definitions of drought, the basic character of drought is that it originates from a deficiency of precipitation. Drought may lead to water shortages that are of considerable concern for urban water supplies, rain-fed agriculture, and ecosystem health (Wilhite and Glantz, 1985). Prolonged dry episodes, consisting of consecutive dry days, can impose high levels of stress on plants (Huth et al., 2000). Drought is a 'creeping phenomenon' (Gillette, 1950), in that even short-term droughts can have a cumulative impact if precipitation deficiencies persist over a considerable period of time (Lei and Duan, 2011).

\subsection{Contending indicators for dry episodes}

\subsubsection{Definitions of dry days}

Several indicators that reveal different aspects of dry episodes are in common use among climate scientists.

\footnotetext{
* Correspondence to: B. Liu, College of Forestry, The Northeast Forestry University, Harbin 150040, China. E-mail: lbinhui@yahoo.com
}

Differing definitions and thresholds make it difficult to compare findings. 'Dry spells' or 'dry episodes' are generally taken to mean a series of consecutive 'dry days'; however, the precipitation threshold for a 'dry day' in previous studies ranges from 0.1 to $10.0 \mathrm{~mm} \mathrm{day}^{-1}$. A $1.0-\mathrm{mm}$ threshold appears to be used most commonly (e.g. Huth et al., 2000; Salinger and Griffiths, 2001; Frich et al., 2002; Diffenbaugh et al., 2005; Moberg and Jones, 2005; Schmidli and Frei, 2005; Haylock et al., 2006; Kruger, 2006; New et al., 2006; Déque, 2007; Groisman and Knight, 2008; Nastos and Zerefos, 2009; McCabe et al., 2010). Higher thresholds have been used in some other studies: $2.0 \mathrm{~mm}$ (Perzyna, 1994), $2.54 \mathrm{~mm}$ (McCabe et al., 2010), $5.0 \mathrm{~mm}$ (Cook and Heerdegen, 2001), and $10.0 \mathrm{~mm}$ (Martin-Vide and Gomez, 1999).

By contrast, previous analyses of trends in dry events in China (e.g. Gong et al., 2005; Lei and Duan, 2011) have used a lower threshold of $0.1 \mathrm{~mm}$, presumably because, for decades, the standard rain gauges used at Chinese meteorological stations have measured precipitation with a resolution of $0.1 \mathrm{~mm} \mathrm{day}^{-1}$. However, there are several factors that can influence the accuracy of precipitation measurement at low levels (Adam and Lettenmaier, 2003). These include the condensation error, the evaporation error, and the wind induced error (Ren et al., 2003). 
These observational errors have a limited effect on annual or seasonal total precipitation, but they may influence how days with low non-zero precipitation are recorded as 'trace precipitation' or as measurable amounts. Such small precipitation events also have a limited effect on soil moisture (Piao et al., 2009).

\subsubsection{Prolonged dry episodes}

Studies consider dry episodes to be 'prolonged' if they are at least 10, 20, or even 60 days in length (e.g. Groisman and Knight, 2008), or exceed some threshold based on normal conditions at individual weather stations (e.g. McCabe et al., 2010). These episodes are long enough to be hydrologically important.

\subsubsection{Prolonged dry episode indicators}

The most common indicator used in characterizing dry episodes within a season or year is the maximum number of consecutive dry days. Other indicators include the mean length of prolonged dry episodes, the frequency of prolonged dry episodes, and the number of days within a season or year that fall into prolonged dry episodes (Salinger and Griffiths, 2001; Frich et al., 2002; Gong et al., 2005; Haylock et al., 2006; Kruger, 2006; Déque, 2007; Liu et al., 2008a; Nastos and Zerefos, 2009).

Changes in total precipitation amount do not necessarily produce synchronous changes in dry spell frequency or duration (Gong et al., 2005). Disproportionate changes in different classes of precipitation eventsspecifically, increases in the very heaviest precipitation events - play an important role in changes of prolonged dry episodes in warm climates (Groisman and Knight, 2008).

Groisman and Knight recently proposed using the number of days in prolonged dry episodes as an index of short-term dry conditions, reflecting the combined effect of the mean length and the frequency of prolonged dry episodes (Groisman and Knight, 2008). They found that the number of dry days within prolonged dry episodes (DDPDE) is not congruent with the widely used Palmer drought severity index (PDSI). This situation may arise when a period of unusually heavy precipitation is followed by a prolonged dry period; thereafter, if another heavy rain event occurred, PDSI calculations would not indicate drought conditions. These circumstances can be expected to arise more often in the future, as observational evidence has confirmed that intense precipitation events are changing at a much faster rate than the total precipitation amount under global warming conditions (Groisman et al., 2005; Liu et al., 2005; Trenberth, 2011). In order to reveal the impact of dry spells on an area, Groisman and Knight suggested that indicators should take better account of both the frequency and mean length of prolonged dry episodes, and proposed taking the total number of DDPDE as a new index to reflect short-term dryness.

In their study of regions of the conterminous United States, Groisman and Knight found that the southwestern region shows an increase in the length of prolonged dry episodes. This is in general agreement with evidence of increased drought conditions in parts of the western United States in the late 20th century (despite the overall national trend towards wetter conditions) (Solomon et al., 2007; Karl et al., 2008; Balling and Goodrich, 2010). However, a subsequent study failed to find such an increase in the southwestern United States, and concluded that 'most sites indicate negative trends in dry event length' (McCabe et al., 2010). McCabe et al. (2010) attribute their different finding to their use of a more reliable data source, the Weather Bureau-Army-Navy weather station network, contending that 'the completeness and quality of the data set used in our study is likely to yield results that are more indicative of the actual pattern of change in dry day events in the southwestern United States than results obtained using data from the cooperative station network' presented by Groisman and Knight (2008). While differences in data quality may play a role in the conflicting findings, we note that the different indices used in the two studies may partly be responsible for the differing conclusions. To test whether such methodological issues might produce the different results found by the two studies of the southwestern United States, in this paper we adapt their methods for a comparably sized region of China using a consistent and quality-controlled data set.

\subsection{Precipitation trends in Northeast China}

Northeast China is located in the northern realm of the Eastern Monsoon. With a humid temperate climate, Northeast China is entirely dominated by the alternating continental and maritime monsoons. Because of its high latitude $\left(39^{\circ}-53^{\circ} \mathrm{N}\right)$, it is the coolest region in China with an annual mean temperature of $5.25^{\circ} \mathrm{C}$ and long, severe winters. Average rainfall decreases from the southeast corner of the region $(900 \mathrm{~mm})$ to the northwest $(400 \mathrm{~mm})$ along with distance from the sea. The growing season coincides with the timing of most precipitation in the summer. This region is an important base for commercial food grains (wheat, rice, and maize) and economic crops (soya and sugar beets) as well as forestry.

While recent warming trends have created more favourable conditions for agricultural development in this region, changes in the frequency and length of prolonged dry periods can have a serious impact on these activities. Recent studies have documented decreased days of frost and a prolonged growing season (Liu et al., 2008b, 2010). Annual precipitation has generally decreased over the past half century, with seasonal differences; changes in extreme precipitation events account for most of the observed trend (Liu et al., 2005). Meanwhile, the frequency of precipitation events $\left(\geq 0.1 \mathrm{~mm} \mathrm{day}^{-1}\right)$ shows a significant decreasing trend in this region, both annually and within individual seasons (Zhai et al., 1999; Gong et al., 2004; Liu et al., 2005; Wang et al., 2006; Qian et al., 2007). Although researchers disagree whether the changes in extreme precipitation are proportional or disproportional to the change in annual total precipitation (Michaels et al., 2004; Liu et al., 2005; Liu et al., 2011a), the changes in light precipitation events $\left(0.1-0.3 \mathrm{~mm} \mathrm{day}^{-1}\right)$ contributed most of the changes in precipitation frequency (Liu et al., 2011b). 
Several previous studies have examined changes in dry spells in Northeast China. Gong et al. (2005) report a statistically significant increasing trend in the frequency of long dry spells ( $\geq 10$ days in length), a non-significant decreasing trend in mean length of long dry spells and a non-significant increasing trend in the maximum length of dry spells during the summer half-year from 1956 to 2000. Lei and Duan (2011) find a significant increase in the duration of prolonged dry episodes across Northeast China within the wet season for the period 1958-2008, when defined as the 90th percentile of periods without measurable precipitation. These two studies define dry days as below $0.1 \mathrm{~mm}$ day $^{-1}$, which is lower than the commonly used threshold of $1.0 \mathrm{~mm} \mathrm{day}^{-1}$. Frich et al. (2002) used the annual maximum number of consecutive dry days to analyse trends in short-term dryness for the period 1946-1999, defining dry days as below $1 \mathrm{~mm} \mathrm{day}^{-1}$; they found a general increasing trend in most of Northeast China except for some stations on the eastern edge of the region. Qian and Lin (2005) analysed changes in maximum number of consecutive dry days $\left(<1 \mathrm{~mm} \mathrm{day}^{-1}\right)$ from 1961 to 2000 , finding that the annual maximum number of consecutive dry day shows a mix of increasing and decreasing trends in Northeast China, with most of the trends not statistically significant.

These previous studies set the threshold for dry days at either 0.1 or $1.0 \mathrm{~mm} \mathrm{day}^{-1}$, and analysed the changes in the maximum number of consecutive dry days during the warm season (Gong et al., 2005, using a threshold of $0.1 \mathrm{~mm} \mathrm{day}^{-1}$ ); during the dry and wet seasons (Lei and Duan, 2011, using a threshold of $0.1 \mathrm{~mm} \mathrm{day}^{-1}$ ); or annually (Frich et al., 2002; Qian and Lin, 2005, using a threshold of $1.0 \mathrm{~mm} \mathrm{day}^{-1}$ ). The differences in thresholds and seasons examined in these studies made them difficult to compare.

The objective of this study is to examine in detail the variability and trends in the frequency of dry days and prolonged dry episode in Northeast China. To test whether methodological issues might produce the different results found by the two studies of the southwestern United States, in this paper, we adapt their methods for a comparably sized region of China using a consistent and quality-controlled data set. Our research tests the index proposed by Groisman and Knight (2008), which incorporates both the frequency and the mean length of prolonged dry episodes in characterizing prolonged dry episodes.

\section{Data and methods}

\subsection{Data, indicators, and thresholds}

Data for this study consist of daily records provided by the China Meteorological Administration (CMA). The data set includes daily precipitation measurements from 34 stations in Northeast China from 1951 through 2008. The 34 stations are well distributed across Northeast China (Figure 1).

As emphasized by McCabe et al. (2010), the consistency and completeness of measurements are of particular



Figure 1. Geographical distribution of the 34 weather stations in Northeast China, highlighting 8 selected stations and their average annual precipitation (mm). The small map in the right corner shows the location of Northeast China (in dark grey).

importance to a study of dry days. CMA protocols specify that measurements at all weather stations are made using the same standards and instrumentation. We have also taken additional measures to assess the homogeneity of the data used in this analysis (Liu et al., 2005). We have excluded records prior to 1960 because of inconsistent or missing measurements in some stations. For subsequent years, records from the 34 stations have been assessed to assure consistency and quality, with a minimum of 99.97\% data availability for each station. No single station accounted for more than four missing observations or two consecutive missing observations. Therefore, the missing data should have a minimal impact on our results.

The indicators we calculated for each season include:

- total seasonal precipitation amount $(\mathrm{mm})$;

- the number of dry days $(<1.0$ and $<2.0 \mathrm{~mm})$;

- the number of prolonged dry episodes (dry spells of $\geq 10$ days);

- the mean length of prolonged dry episodes; and

- the number of DDPDE.

A dry episode is defined as a series of consecutive days with daily precipitation of less than a certain threshold: a dry episode is preceded and followed by rainfall days exceeding the threshold (She and Xia, 2012). It is worth noting that while the accumulation of dryness is gradual, its termination is sudden and sharp. Delineating dry episodes relies on the selection of the threshold, and analyses of dry episodes could be done using different rainfall thresholds (Suppiah and Hennessy, 1998; Nastos and Zerefos, 2009). Although, as noted above, most prior studies on the changing character of dry episodes in China have defined dry days as below $0.1 \mathrm{~mm}^{-1} \mathrm{day}^{-1}$, observational errors may influence the accuracy of precipitation measurements at these low levels. The use of higher thresholds eliminates the excessive weight that some isolated rainy days with small amounts have in breaking a long dry episode (Mathugama and Peiris, 2011). In 
this study, dry episodes are computed based on two daily rain thresholds, 1.0 and $2.0 \mathrm{~mm}^{-1 a y^{-1}}$. Thresholds above $2 \mathrm{~mm} \mathrm{day}^{-1}$ were considered but are not used here because of the scarcity of observations for the winter half-year at some sites.

Selecting the 1- and 2-mm thresholds avoids potential measurement inconsistencies and recognizes that smaller amounts of rain may evaporate directly without replenishing soil moisture (Groisman and Knight, 2008). At the season boundaries, dry spells are allocated to the season in which the larger part falls. In the case of a dry spell falling at a season boundary with an equal duration in both seasons, the dry spell is allocated to the later season.

The frequency of prolonged dry episodes and the mean length of prolonged dry episodes are two indicators of dry conditions in a season. DDPDE reflects the combined effect of these two indicators. Changes in DDPDE over time can better reflect the trends in dry conditions than either the frequency or length indicators alone (Groisman and Knight, 2008).

\subsection{Season divisions}

Studies of dry episodes in other areas reveal that there are great differences in the character of dry episodes between wet and dry seasons (Kutiel, 1985; Reiser and Kutiel, 2010). To test whether these differences can be observed in Northeast China, we first analysed the temporal distribution of dry episodes for each station during the year in order to see whether seasonal differences exist. Next, we compared the results of different stations to identify spatial patterns.

The annual distribution of dry conditions can be represented by the index of DDSLR (dry days since last rain) (Kutiel, 1985; Aviad et al., 2009). The DDSLR index is defined as the time since the last day of rain (with rain above the threshold for dry days). DDSLR enables evaluating the dryness conditions for every day throughout the year, regardless if it is the first or the last day of a dry spell. The median and other parameters of DDSLR for each day provide probabilistic information regarding the course of dryness during the year (Aviad et al., 2009). For each day, if precipitation above the dry day threshold is reported (a wet day), the value of 0 is assigned; the first dry day after a wet day is given the value of 1 , with subsequent consecutive dry days numbered in ascending order. In order to obtain the same length for every calendar year, we excluded February 29 in leap years. Thus, each of the 365 days of the year was assigned 49 values (one for each of the 49 years of observations, from 1960 to 2008).

April 1 is taken as the first day of the analytical year; March 31 of the next year is taken as the 365 th day. Northeast China is dominated by the alternating continental or winter and maritime or summer monsoons. By late March, the winter monsoon becomes weaker and retreats from south to north. This is the important reason why we set April as the beginning of the analytical year. This does not affect the calculations or the results pertaining to the length of the dry spells, and it was done only for convenience purpose (Kutiel, 1985).
Arranging the 49 values of each day in ascending order, we find that they generally show a skewed frequency distribution: small values occur more frequently than large values. The mean, commonly used to reflect 'normal' conditions, is extremely sensitive to skew because it is inflated by the few cases of large values (Glantz and Katz, 1977). To avoid this problem, we use the median and quartiles to reflect the annual course of the distribution of dry episodes. For each day, the median value and the two quartiles were calculated. The calculated medians and quartiles for each day of the year represent the number of dry days that passed from the last wet day for probabilities of 25, 50, and 75\% (Kutiel, 1985).

Periods with low DDSLR values represent wet conditions, whereas periods with high DDSLR value represent dry conditions. In Northeast China there is a great difference in the length of the dry episodes between the summer or wet half-year (May to October) and the winter or dry half-year (November to April) (see Figure 2 for a selection of eight stations and Figure 3 for the regional average, at the $1 \mathrm{~mm} \mathrm{day}^{-1}$ threshold). The temporal change of DDSLR for threshold of dry day at $2 \mathrm{~mm}^{-1} \mathrm{day}^{-1}$ (not shown) is similar to Figure 2. The temporal change in dry conditions corresponds with the monsoon climate in this area. During the winter half-year, DDSLR values show a sharp increase until February, and then decrease sharply until April. During the summer half-year, DDSLR values are generally low with little change. The parallel tracks of the $25 \mathrm{th}, 50 \mathrm{th}$, and 75 th percentiles in these graphs are similar to the results seen for other areas (Reiser and Kutiel, 2010). The DDSLR graphs reveal the periodicity of dry episodes during the year, with generally longer dry episodes peaking in the winter half-year. We can infer from the temporal distribution of dry episodes that the annual maximum number of consecutive dry days generally occurs during the winter half-year. Thus, previous research studies on the change in the annual maximum number of consecutive dry days in Northeast China by Frich et al. (2002) and Qian and Lin (2005) generally reflect the changes of the longest dry episodes during the winter half-year. While the eight stations highlighted in Figure 1 display obvious differences in average annual precipitation, Figure 2 reveals that they have similar cycles in the dry spell length throughout the year. The other 26 stations across the region reveal similar annual distributions of dry episodes. This fact indicates that the two-season cycle in the length of dry spells is a general phenomenon related to the regional factors affecting the rainfall regime in Northeast China. Thus, to detect changes in the length and frequency of dry spells in Northeast China, separate analyses of the two seasons (the summer and winter half-years) are needed.

\subsection{Analysing Trends and Reporting Significance}

In our analysis, we first calculated the anomaly of each indicator based on the period average for each station for each summer (wet) half-year and winter (dry) half-year. We then calculated trends of each indicator for the summer and winter half-years for each site. To characterize 

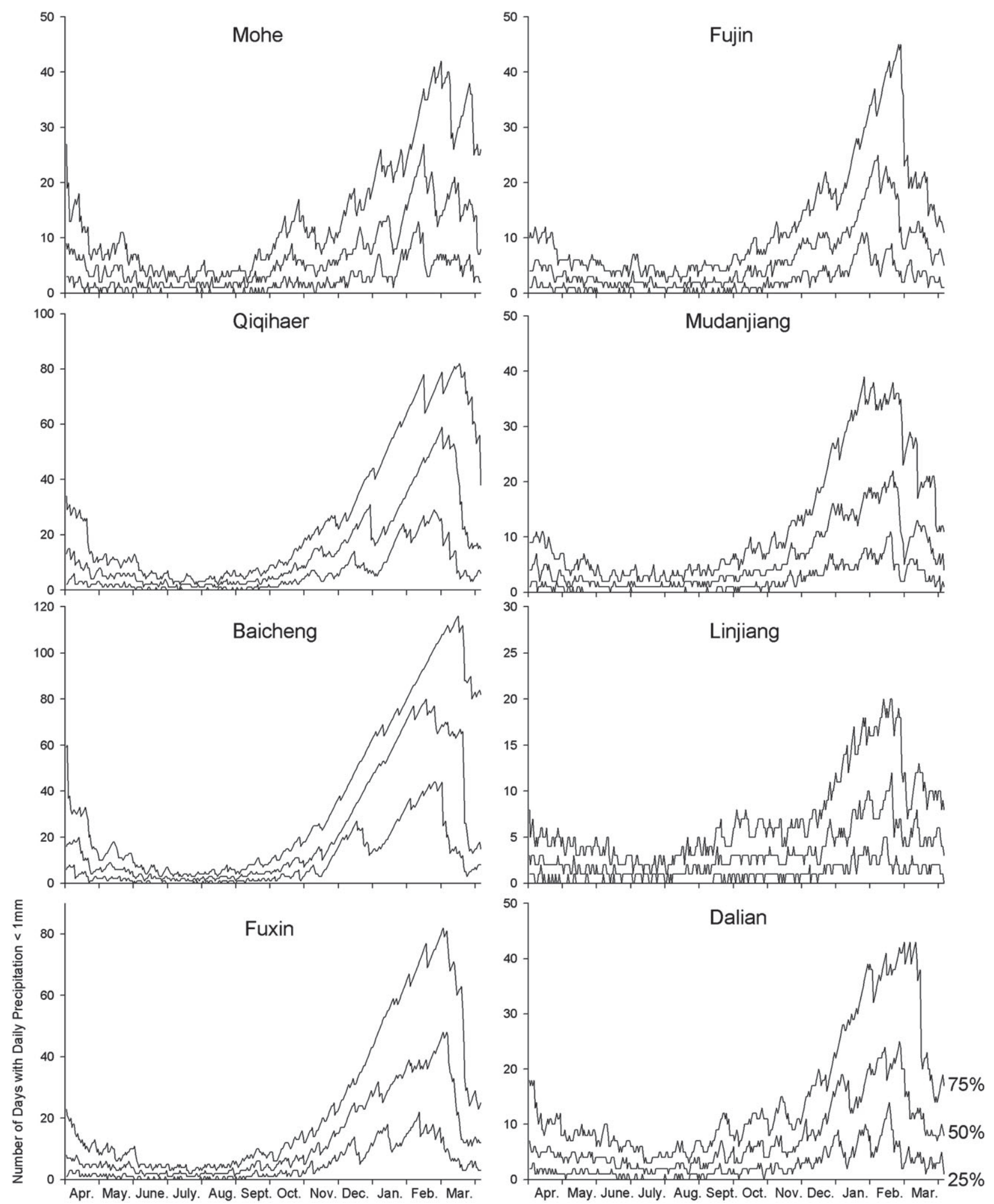

Figure 2. Annual distribution of dry days $\left(<1.0 \mathrm{~mm} \mathrm{day}^{-1}\right)$ since last rain at eight selected stations, $1960-2008$.

change across the entire region, we first constructed a time series of each indicator by averaging all the stations' time series values and then calculated the trend. Regression analysis was used to establish the linear trends of the indicators; for the purpose of analysing temporal variation, we applied a nine-point binomial filter, a method to smooth out the year-to-year variations in a time series and show the longer-term trend. Temporal autocorrelation is not a problem in this study because the regression was performed on seasonal basis; we confirmed this by using the Durbin-Watson statistic to test the time series for first-order autocorrelation.

We used the $t$-test to determine whether the linear trends were significantly different from zero at the 5 and $10 \%$ 


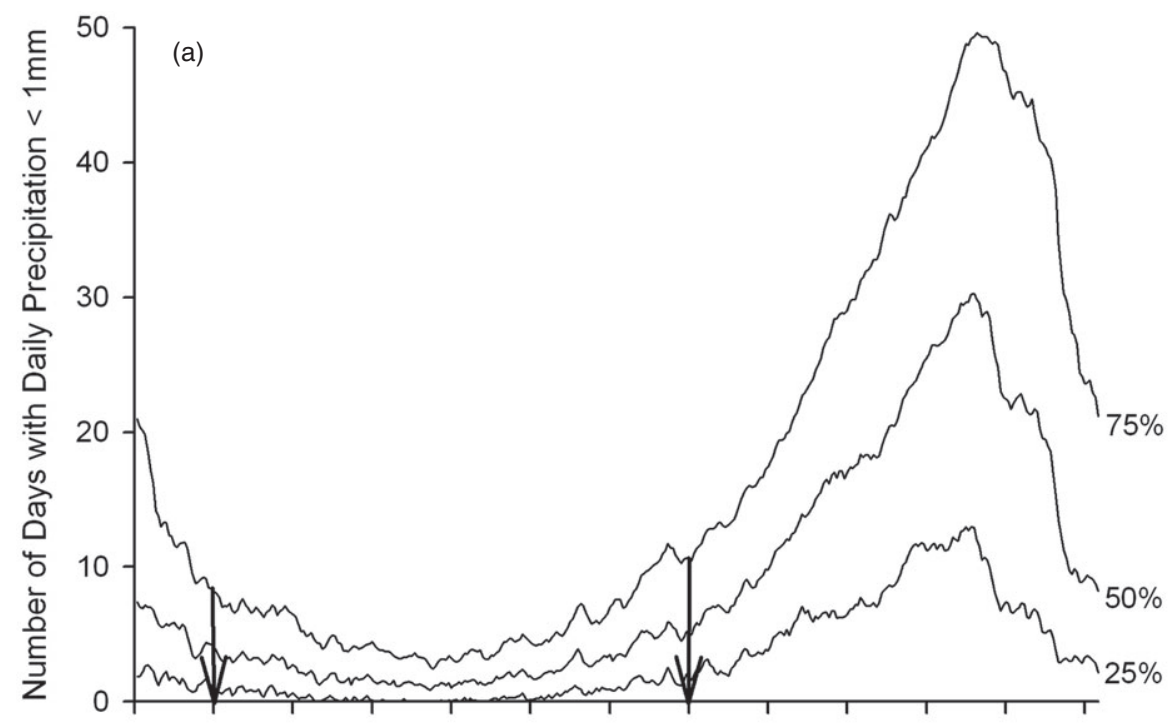

Apr. May. June. July. Aug. Sept. Oct. Nov. Dec. Jan. Feb. Mar.

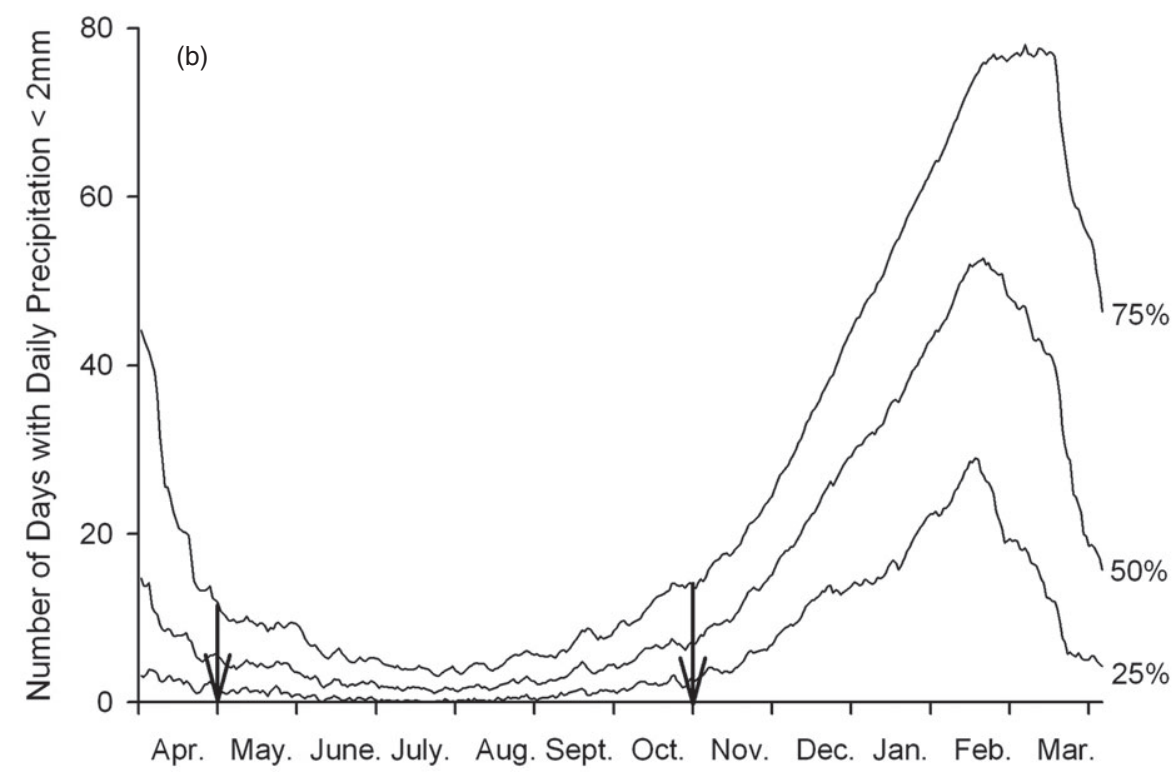

Figure 3. Northeast China regional average annual distribution of dry days since last rain, $1960-2008$. The threshold of dry day is (a) $<1 \mathrm{~mm} \mathrm{day}^{-1}$, (b) $<2 \mathrm{~mm} \mathrm{day}^{-1}$.

probability level. While the $p=0.05$ or $p=0.10$ threshold for statistical significance is the conventional standard for identifying trends, Nicholls (2001) discusses the danger in adopting a dichotomous 'significant/non-significant' attitude towards significance testing and using an arbitrary (e.g. 5\%) standard. A substantial amount of information may be lost if all values that do not reach significance at a certain probability level are rejected (Griffiths and Bradley, 2007). If a high degree of spatial coherence is observed in the trends from multiple stations within a region, it may still be reasonable to conclude that the trends are not the result of random chance, even if the magnitude of the trends is not large compared with the temporal variability. With this in mind, when reporting on regional trends we include the results from all stations; however, we do highlight the number of stations whose trends achieve statistical significance. We expect that if a larger number of geographically clustered stations show parallel trends, a non-random process may be at work.

Adapting the method proposed by Karl and Knight (1998), we estimated the proportion of any trend in DDPDE that is attributable to changes in the mean length of prolonged dry episodes as opposed to changes in the frequency of those episodes. This is calculated for the frequency component by determining the average mean prolonged dry episode length for the period ( $D l \_$mean) and the trend in the frequency of prolonged dry episode $(F d)$. Then the change in DDPDE due to the trend in the frequency of prolonged dry episode is simply defined by

$$
D f=D l \_ \text {mean } \times F d
$$

In this analysis, $D f$ is expressed as days season ${ }^{-1}$. For the changes in the mean length of prolonged dry episode component, the trend is directly calculated as a residual 

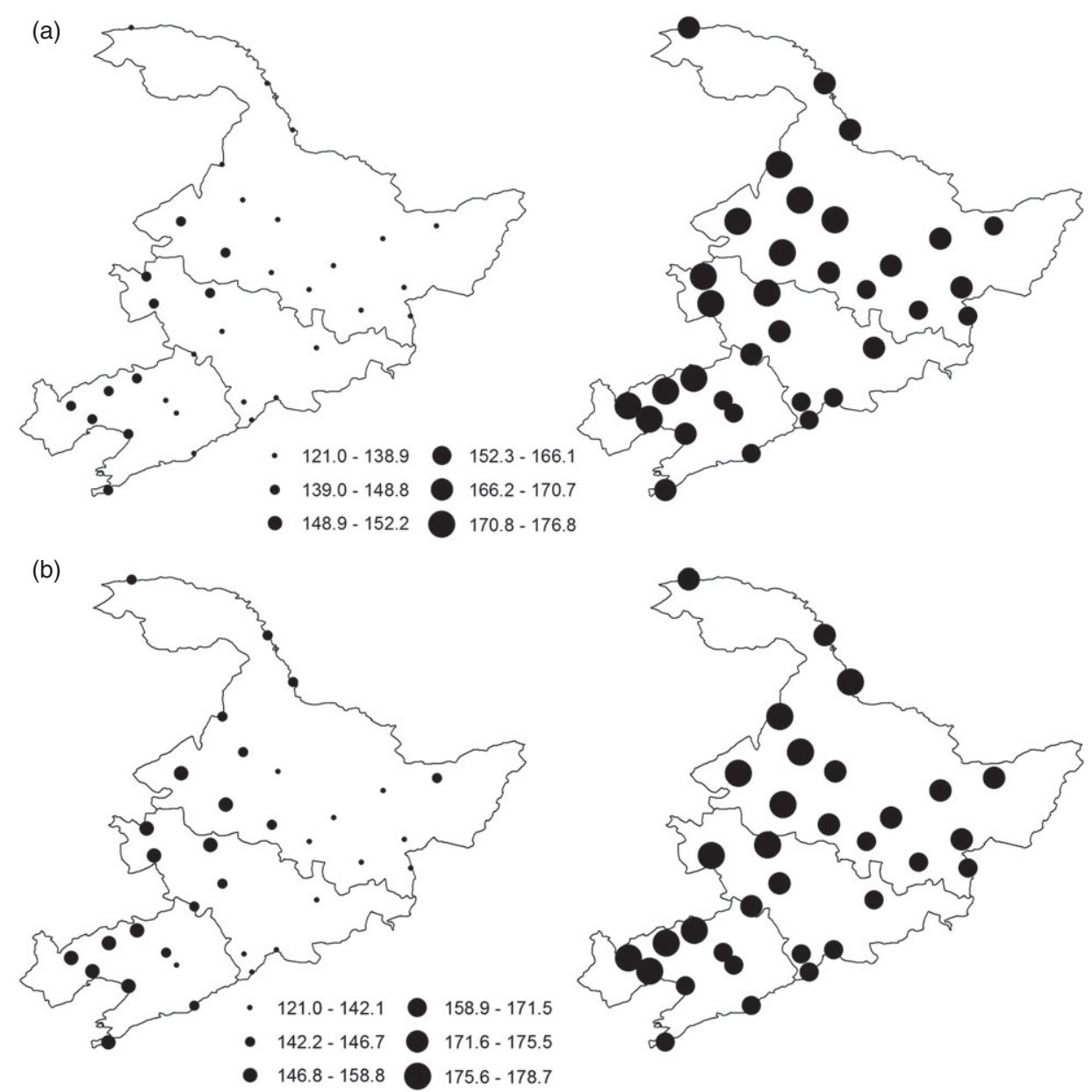

Figure 4. Climatology of number of dry days during summer half-year (left) and winter half-year (right). The threshold of dry day is (a) $<1 \mathrm{~mm} \mathrm{day}^{-1}$, (b) $<2 \mathrm{~mm} \mathrm{day}^{-1}$.

using the expression

$$
D l=D-D f
$$

where $D$ is the trend in DDPDE.

\section{Results and discussion}

3.1. Long-term average characteristics of prolonged dry episodes

Figure 4 shows the mean numbers of dry days $(<1$ and $<2 \mathrm{~mm}$ ) in the summer and winter half-years over the entire study period 1960-2008. The winter half-year generally has more dry days than the summer half-year. Stations in the western part of the region generally have more dry days than those in the eastern part. These correspond with the water conditions in Northeast China, where annual precipitation is mainly distributed in the summer half-year and the eastern part of the region has more precipitation than the western part.

The mean frequency of prolonged dry episodes in the summer and winter half-years over the study period is presented in Figure 5. During the summer half-year, stations in the western part of the region generally have more prolonged dry episodes than those in the eastern part; but the spatial pattern is reversed in the winter half-year. For the threshold of $1 \mathrm{~mm}$, the winter half-year generally has more prolonged dry episodes than the summer half-year; there are only four stations in the west where the summer half-year has more prolonged dry episodes. For the threshold of $2 \mathrm{~mm}$, stations in the eastern part of the region during the winter half-year generally have more prolonged dry episodes than during the summer half-year, but stations in the west part of the region in the winter half-year generally have less prolonged dry episodes than in the summer half-year.

The average mean length of prolonged dry episodes in the summer and winter half-years for 1960-2008 is shown in Figure 6. On average, the winter half-year has much longer prolonged dry episodes than the summer half-year, and the western part of the region generally has longer prolonged dry episodes than the eastern part. Comparing Figure 5 with Figure 6, we can find the opposite distribution of mean length of prolonged dry episodes and frequency of prolonged dry episodes during winter half-year, irrespective of the threshold level. The western part of the region in winter half-year is characterized by a low number of prolonged dry episodes with long length, especially for threshold of $2 \mathrm{~mm}$. 
(a)

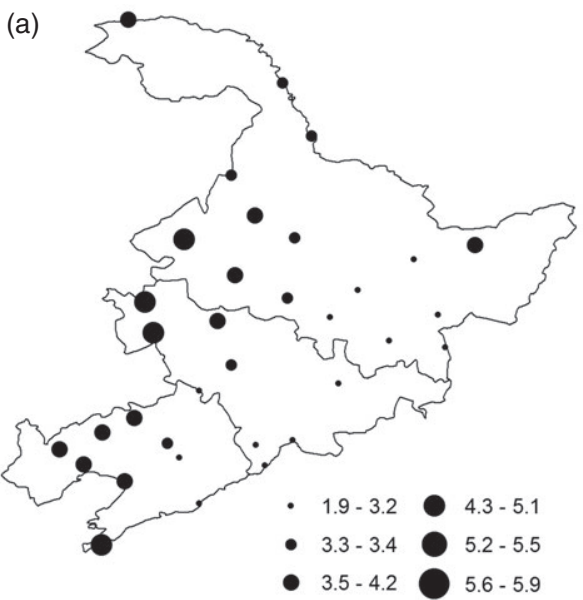

(b)
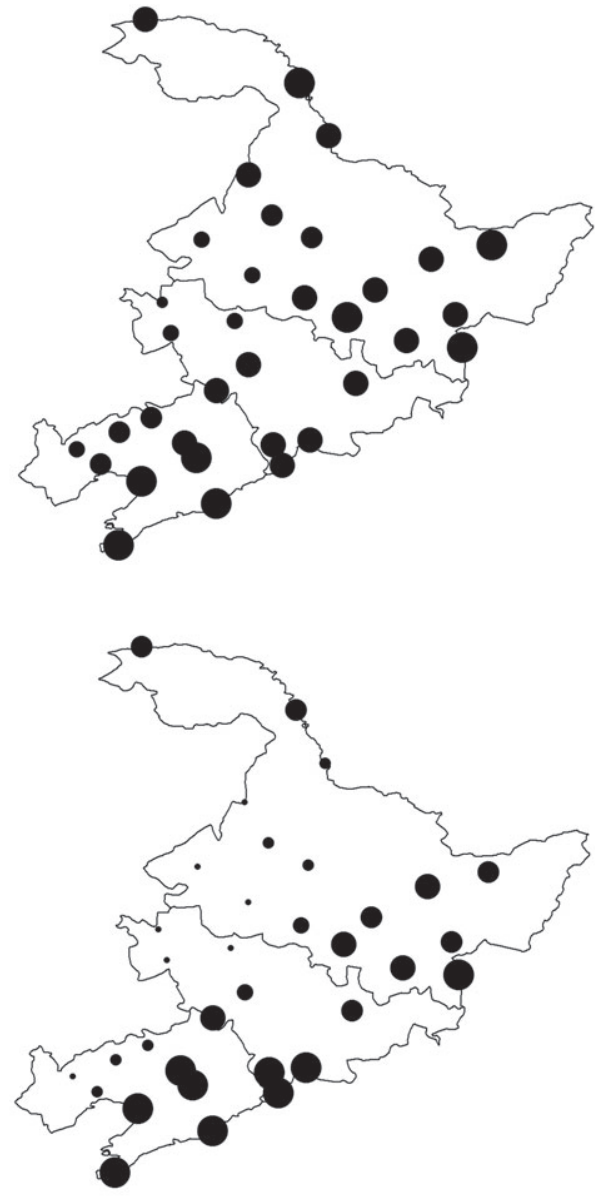

Figure 5. Climatology of the frequency of prolonged dry episodes during summer half-year (left) and winter half-year (right). The threshold of dry day is (a) $<1 \mathrm{~mm}$ day $^{-1}$, (b) $<2 \mathrm{~mm} \mathrm{day}^{-1}$.

Figure 7 shows the mean number of DDPDE in the summer and winter half-years at stations in Northeast China for the period 1960-2008. DDPDE is greater in the winter half-year and in the western part of the region, less in the summer half-year and in the eastern part of the region. The durations of the prolonged dry episodes are generally longer in the winter half-year, implying a higher risk of short-term drought than in the summer half-year. It should be pointed out that for threshold of $2 \mathrm{~mm}$, during the winter half-year, several stations in the western part of the region have a mean DDPDE larger than the total length of the winter half-year. This is because at these stations there are very few wet days with precipitation $\geq 2 \mathrm{~mm}$ during the winter half-year, and dry spells that cross the season boundaries are allocated to the season in which the larger part falls.

Comparing Figure 4 with Figure 7, we observe that a relatively high percentage of the winter's dry days are concentrated within prolonged dry episodes, while the percentage for the summer half-year is much lower. Focusing on the winter, we can see some geographical differences within the region: there are more dry days and longer dry episodes in the west, but more frequent dry episodes in the east. In other words, dry spells in the east are more likely to be interrupted by days with precipitation; the higher frequency of prolonged dry episodes does not mean that drought conditions are more severe in this part of the region. This reinforces the importance of looking at both the frequency and the duration of prolonged dry episodes. DDPDE, as a function of both the frequency and length of prolonged dry episodes, can provide a better measure of general short-term dry conditions.

When we compare different indicators over the long term, we find similar spatial patterns in the number of dry days, the mean length of prolonged dry episodes, and DDPDE, for all threshold levels tested. The 2-mm threshold naturally produces greater numbers of dry days, longer prolonged dry episodes, and higher DDPDE values. During the summer half-year, the 2-mm threshold produces more prolonged dry episodes, but during the winter half-year, 1-mm threshold produces more (but shorter) episodes, as precipitation events of between 1 and $2 \mathrm{~mm}$ break up the episodes (Figure 5).

3.2. Station trends and spatial changing characteristics of prolonged dry episodes

Calculating trends for the number of dry days each year over the 1960-2008 study period, most of the 34 sites in Northeast China show positive trends for the summer 
(a)
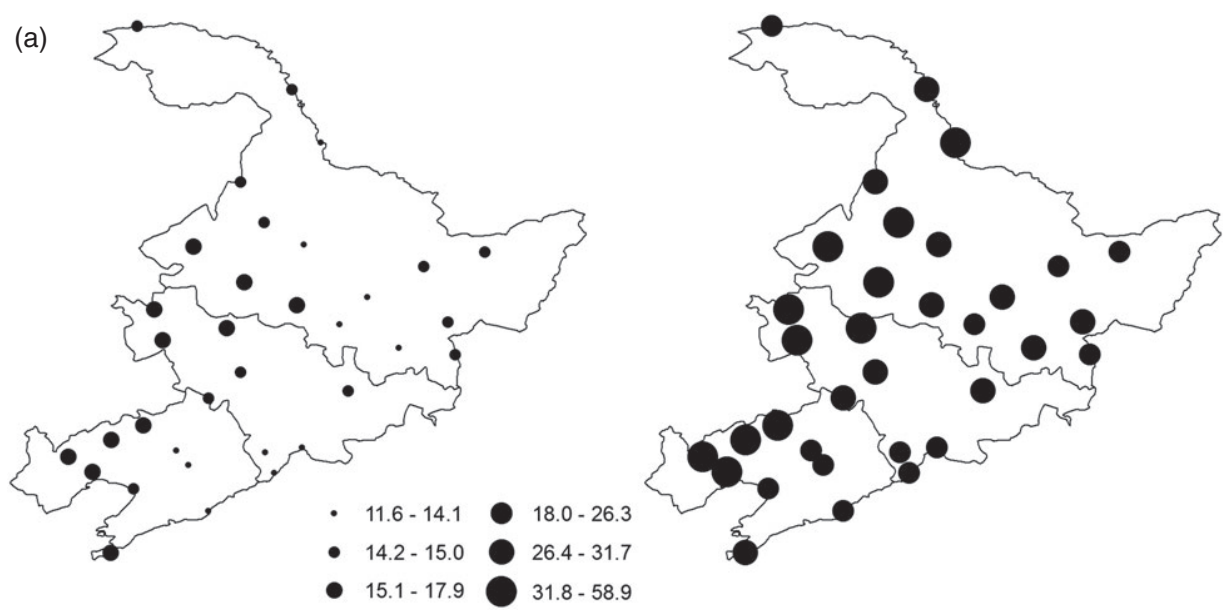

(b)
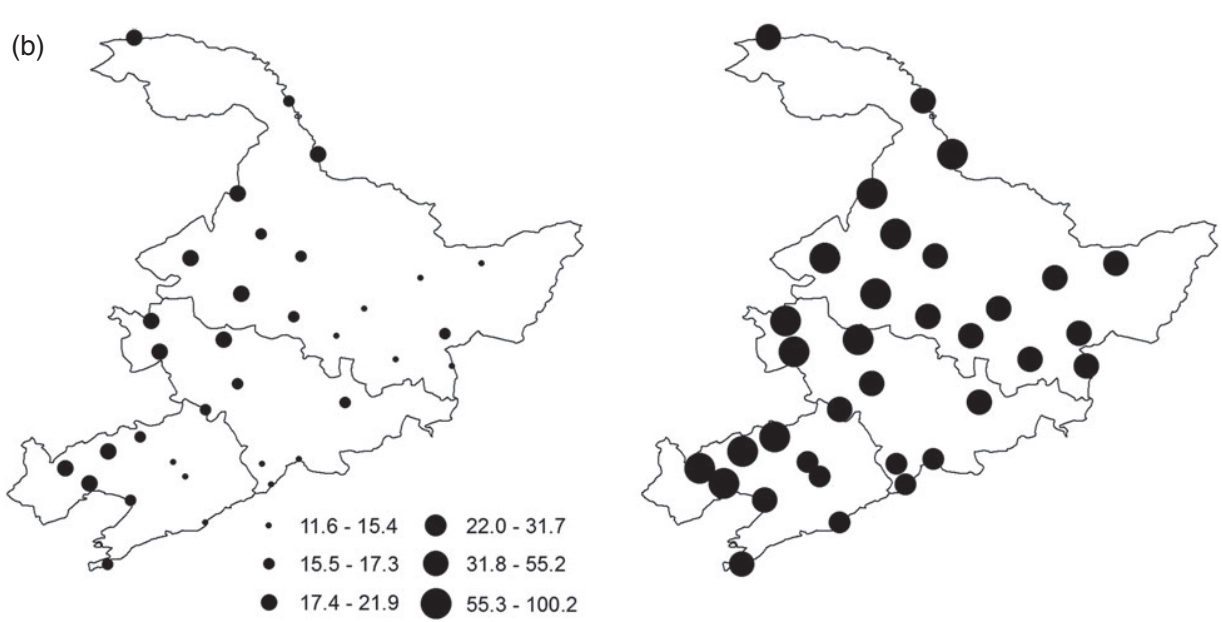

Figure 6. Climatology of the mean length of prolonged dry episodes during summer half-year (left) and winter half-year (right). The threshold of dry day is (a) $<1 \mathrm{~mm} \mathrm{day}^{-1}$, (b) $<2 \mathrm{~mm} \mathrm{day}^{-1}$.

half-year and negative trends for the winter half-year (Figure 8 and Table 1). (As noted above, following Nicholls, 2001 and Griffiths and Bradley, 2007, we report on regional trends with reference to spatially coherent patterns at all sites, while highlighting sites with statistically significant trends at the 90 and $95 \%$ confidence levels.) For the threshold of $1 \mathrm{~mm}$ during the summer half-year, 33 sites exhibit positive trends (with 13 sites achieving statistical significance at $p=0.05$, or 18 sites achieving statistical significance at $p=0.10$ ); only 1 site displays a negative (and non-significant) trend. During the winter half-year, 29 sites exhibit negative trends (with 5 achieving statistical significance at $p=0.05$, or 8 sites at $p=0.10$ ) and only 5 displaying positive trends (all non-significant). Trends in the number of dry days over the threshold of $2 \mathrm{~mm}$ generally repeat the pattern for the threshold of $1 \mathrm{~mm}$, with positive trends during the summer half-year but negative trends during the winter half-year.

The frequency of prolonged dry episodes has increased at most sites in both summer and winter (Figure 9 and Table 1). For the threshold of $1 \mathrm{~mm}$, during the summer half-year, 31 sites have positive trends (10 sites are significant at $p=0.05$ or 14 sites at $p=0.10$ ). These, in general, correspond with the increased trends in the number of dry days for most of sites. For the winter half-year, 21 sites have positive trends ( 2 sites are significant at $p=0.05$ or 4 sites at $p=0.10)$. No sites have statistically significant negative trends. Comparing the trends of Figures 8 and 9 , we find the decreasing number of dry days in winter does not always correspond to a decline in the frequency of prolonged dry episodes. For the threshold of $2 \mathrm{~mm}$, the pattern in the frequency of prolonged dry days in the summer half-year is similar to the 1-mm threshold pattern. During winter half-year, for the threshold of $2 \mathrm{~mm}$, there are more sites with positive trends (30 sites, with 3 significant at $p=0.05$ or 7 significant at $p=0.10)$. This is because there are fewer, but longer, prolonged dry episodes for the threshold of $2 \mathrm{~mm}$ increase in wet days (decrease in dry days) have more chance of breaking up the long dry episode.

Considering the mean length of prolonged dry episodes (Figure 10 and Table 1), for the threshold of $1 \mathrm{~mm}$ during the summer half-year, the trends for the summer half-year are roughly balanced between increasing and decreasing estimates, and there only a small number of stations for which the trends are statistically significant: 16 sites show positive trends (no sites are significant at $p=0.05 ; 1$ site is significant at $p=0.10$ ) and 18 show negative trends ( 3 sites are significant at $p=0.05$ or 4 sites at $p=0.10)$. For the winter half-year, 9 sites show positive (but non-significant) 

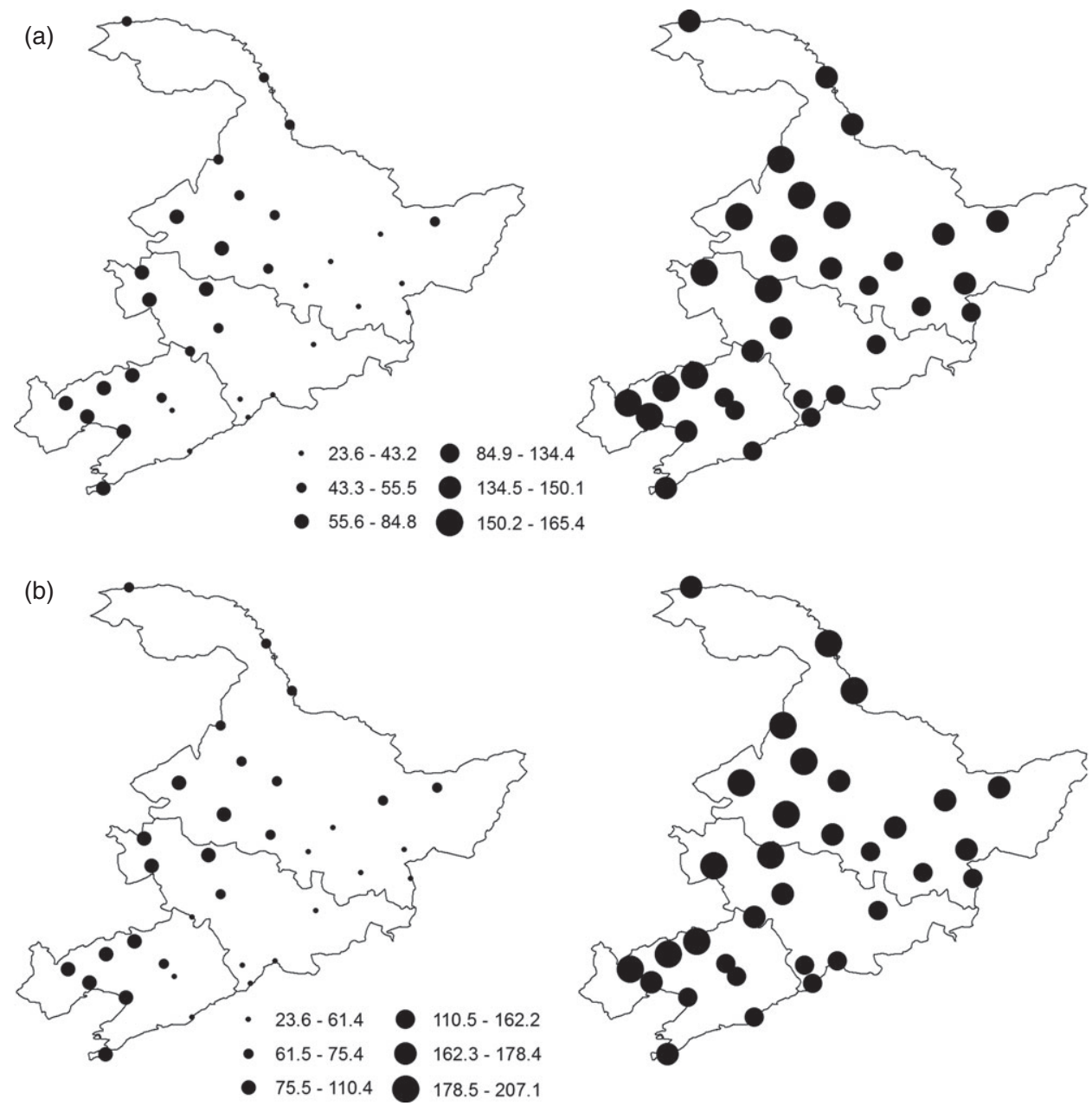

Figure 7. Climatology of dry days within prolonged dry episodes (DDPDE) during summer half-year (left) and winter half-year (right). The threshold of dry day is (a) $<1 \mathrm{~mm} \mathrm{day}^{-1}$, (b) $<2 \mathrm{~mm} \mathrm{day}^{-1}$.

Table 1. Number of sites with positive or negative trends, 1960-2008.

\begin{tabular}{lccccc}
\hline & \multicolumn{2}{c}{ Dry day $\left(<1 \mathrm{~mm} \mathrm{day}^{-1}\right)$} & & \multicolumn{2}{c}{ Dry day $\left(<2 \mathrm{~mm} \mathrm{day}^{-1}\right)$} \\
\cline { 5 - 6 } & Positive & Negative & & Positive & Negative \\
\hline Summer half-year (May to October) & & & & \\
Precipitation amount & $5(0,0)$ & $29(2,10)$ & & $5(0,0)$ & $29(2,10)$ \\
Number of dry days & $33(13,18)$ & $1(0,0)$ & & $34(8,17)$ & $0(0,0)$ \\
Number of prolonged dry episode(>10days) & $31(10,14)$ & $3(0,1)$ & & $28(5,9)$ & $6(0,0)$ \\
Mean dry event length for prolonged dry episodes & $16(0,1)$ & $18(3,4)$ & & $18(0,1)$ & $16(3,6)$ \\
DDPDE & $30(9,14)$ & $4(0,0)$ & & $27(5,7)$ & $7(0,0)$ \\
Winter half-year (November to April) & & & & $6(0,0)$ \\
Precipitation amount & $28(3,6)$ & $6(0,0)$ & & $28(3,6)$ & $31(6,7)$ \\
Number of dry days & $5(0,0)$ & $29(5,8)$ & & $3(0,0)$ & $4(0,0)$ \\
Number of prolonged dry episode(>10 days) & $21(2,4)$ & $13(0,0)$ & & $30(3,7)$ & $28(5,5)$ \\
Mean dry event length for prolonged dry episodes & $9(0,0)$ & $25(4,6)$ & & $6(0,0)$ & $13(1,1)$ \\
DDPDE & $8(0,0)$ & $26(2,4)$ & $21(0,0)$ & \\
\hline
\end{tabular}

Number of sites with significant trends (95\%, $90 \%$ confidence level ) are indicate in parentheses.

trends and 25 show negative trends (4 sites are significant at $p=0.05$ or 6 sites at $p=0.10$ ). Trends in the mean length of prolonged dry episodes for the threshold of $2 \mathrm{~mm}$ repeat the general pattern seen with the threshold of $1 \mathrm{~mm}$. This indicates that the increasing number of summer dry days does not always correspond with an increase in the duration of prolonged dry episodes; however, the winter decline in the number of dry days does correspond with a shortening of prolonged dry episodes at most sites. Thus, change in the number of dry days does not necessarily produce synchronous changes in the mean length (as seen in the summer half-year) of prolonged dry episodes.

Trends in DDPDE (shown in Figure 11 and Table 1) are mostly positive in the summer half-year and negative in the 

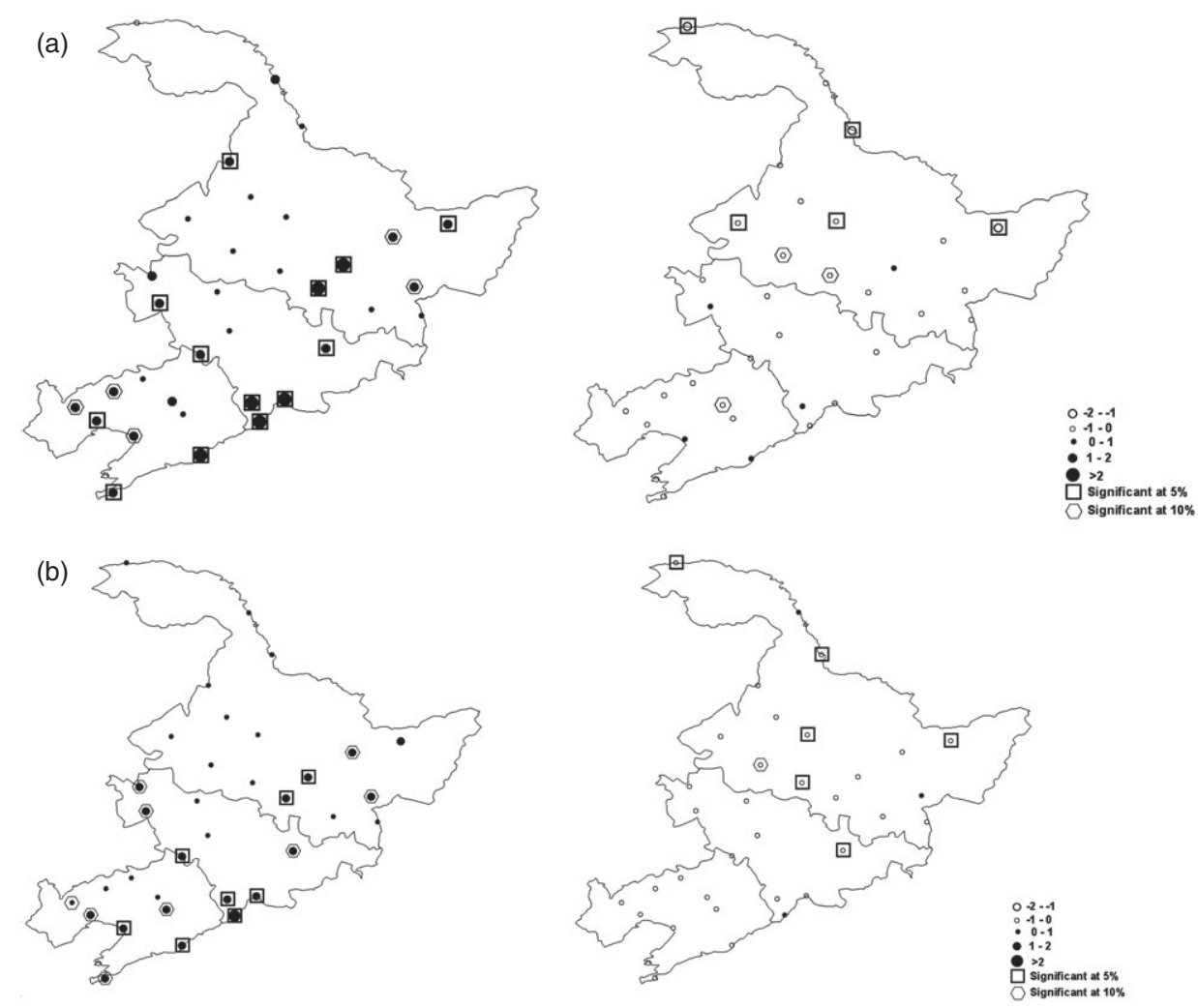

Figure 8. Trend in number of dry days with daily precipitation during summer half-year (left) and winter half-year (right), 1960-2008. The threshold of dry day is (a) $<1 \mathrm{mmday}^{-1}$, (b) $<2 \mathrm{~mm} \mathrm{day}^{-1}$.

(a)

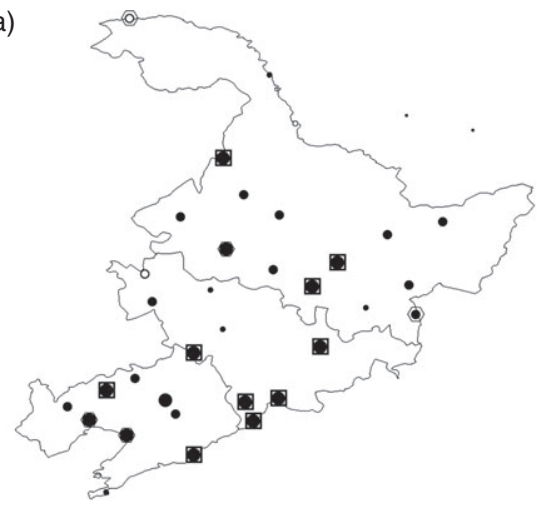

(b)

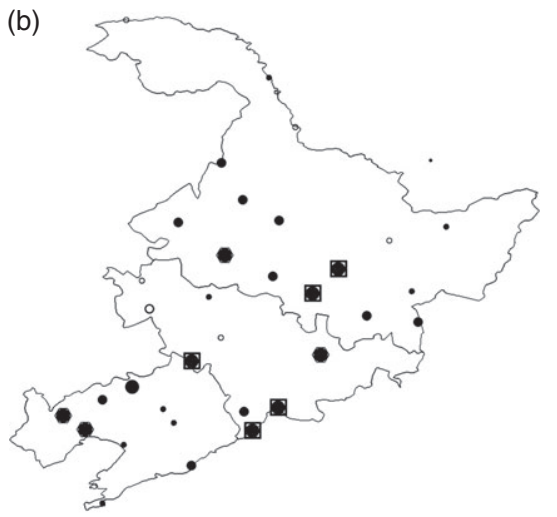

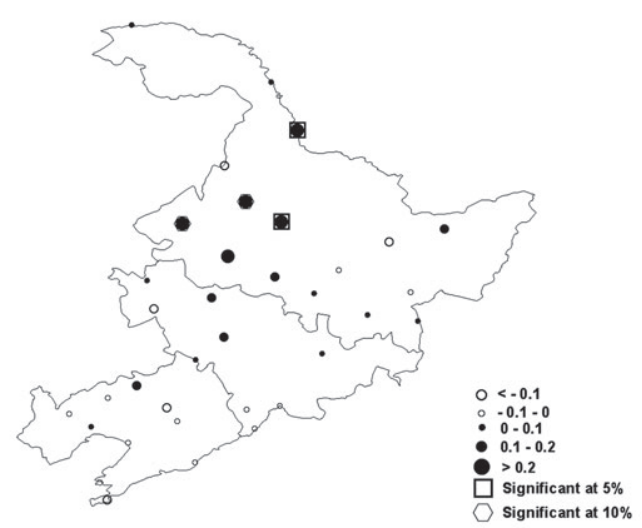

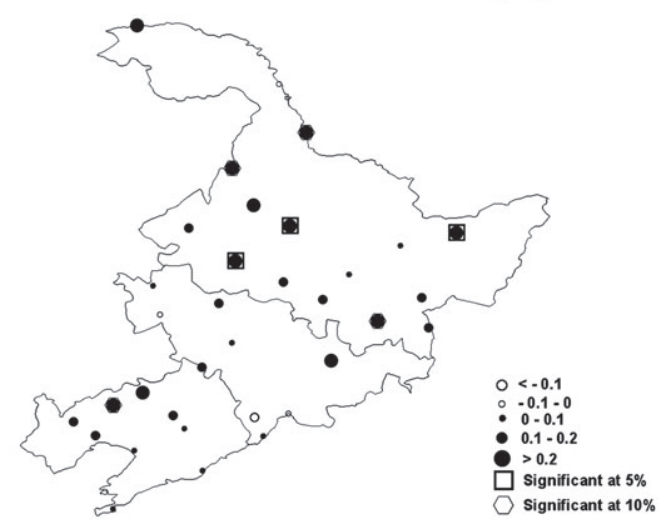

Figure 9. Trend in the frequency of prolonged dry episodes during summer half-year (left) and winter half-year (right), 1960-2008. The threshold of dry day is (a) $<1 \mathrm{mmday}^{-1}$, (b) $<2 \mathrm{~mm} \mathrm{day}^{-1}$. 

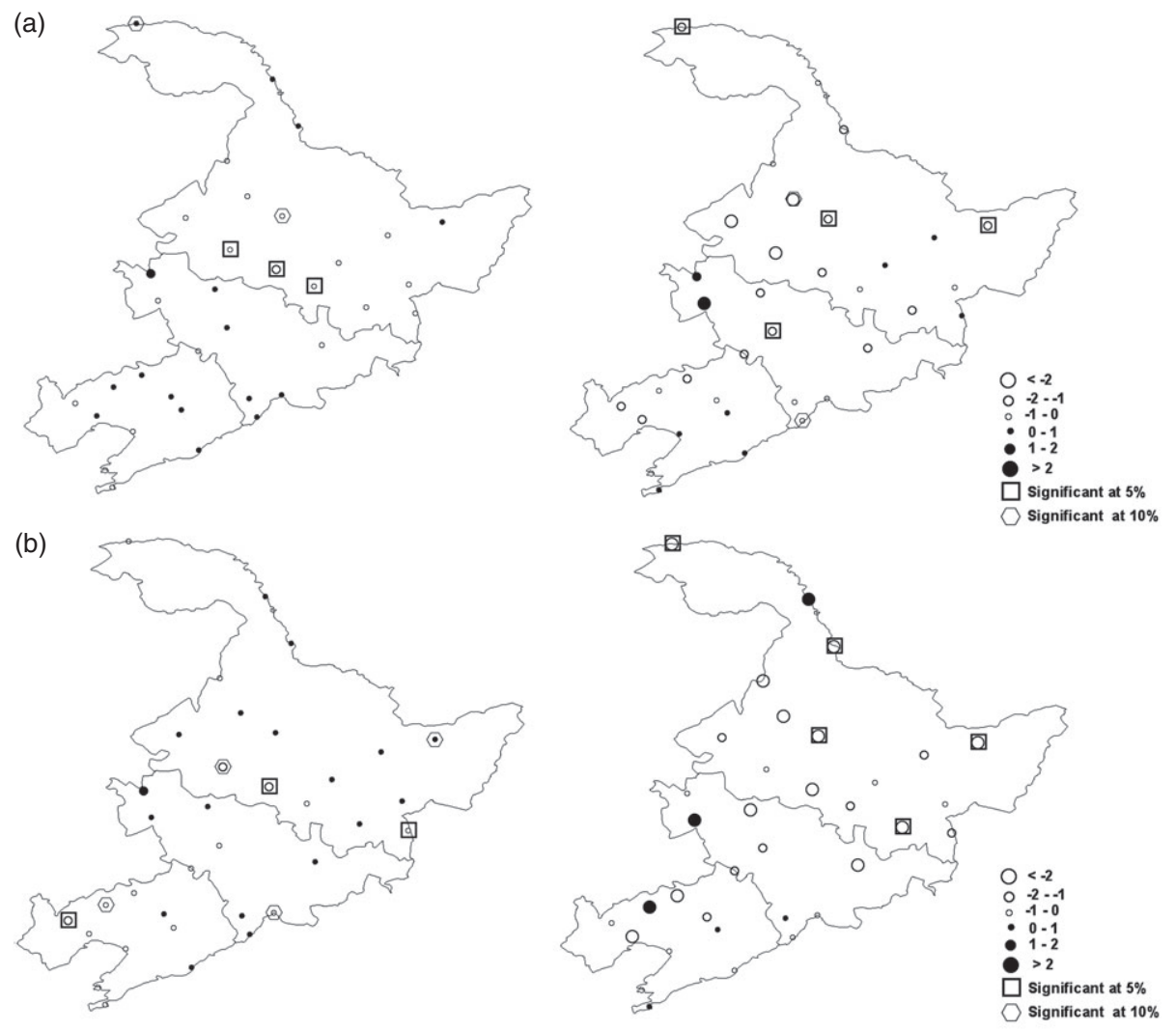

Figure 10. Trend in the mean length of prolonged dry episodes during summer half-year (left) and winter half-year (right), 1960-2008. The threshold of dry day is (a) $<1 \mathrm{~mm} \mathrm{day}^{-1}$, (b) $<2 \mathrm{~mm} \mathrm{day}^{-1}$.
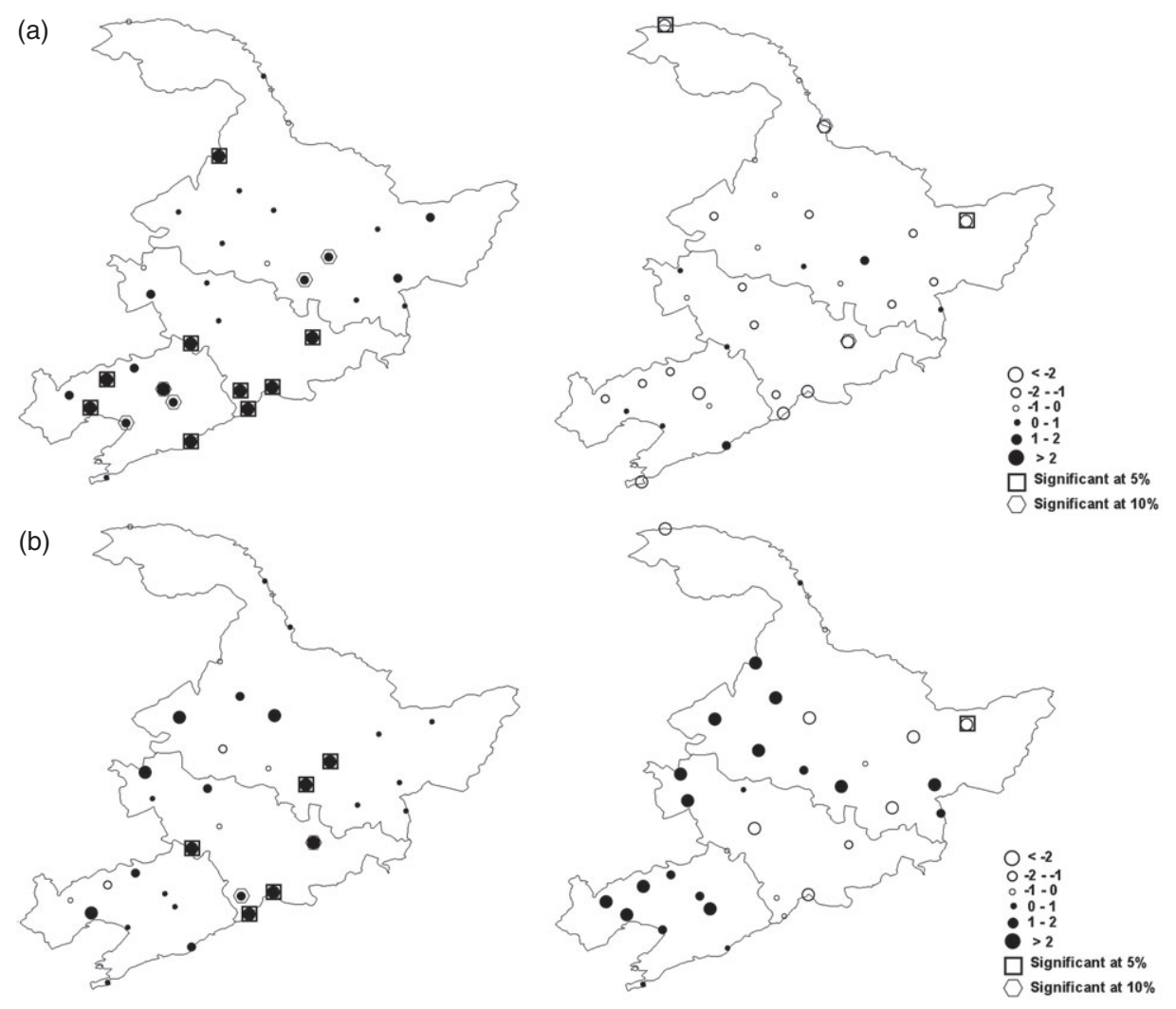

Figure 11. Trend in DDPDE during summer half-year (left) and winter half-year (right), from 1960-2008. The threshold of dry day is (a) $<1 \mathrm{~mm} \mathrm{day}^{-1}$, (b) $<2 \mathrm{~mm} \mathrm{day}^{-1}$. 
Table 2. Trends of selected indices during the summer and winter half-years.

\begin{tabular}{|c|c|c|c|c|}
\hline & \multicolumn{2}{|c|}{ Dry day $\left(<1 \mathrm{~mm} \mathrm{day}^{-1}\right)$} & \multicolumn{2}{|c|}{ Dry day $\left(<2 \mathrm{~mm} \mathrm{day}^{-1}\right)$} \\
\hline & Summer half-year & Winter half-year & Summer half-year & Winter half-year \\
\hline $\begin{array}{l}\text { Precipitation } \\
\text { amount }\left(\mathrm{mm} \mathrm{decade}^{-1}\right)\end{array}$ & $-13.2(-2.6)^{* *}$ & $1.9(2.7)^{* *}$ & $-13.2(-2.6)^{* *}$ & $1.9(2.7)^{* *}$ \\
\hline $\begin{array}{l}\text { Number of dry } \\
\left.\text { days(days decade }{ }^{-1}\right)\end{array}$ & $1.3(0.9)^{* *}$ & $-0.4(-0.2)^{* *}$ & $1.01(0.7)^{* *}$ & $-0.3(-0.2)^{*}$ \\
\hline $\begin{array}{l}\text { Number of prolonged dry } \\
\text { episode(numbers decade }{ }^{-1} \text { ) }\end{array}$ & $0.2(5.9)^{* *}$ & $0.04(0.8)$ & $0.13(3.03)^{* *}$ & $0.14(3.3)^{* *}$ \\
\hline $\begin{array}{l}\text { Mean dry event length for } \\
\text { prolonged dry episodes } \\
\left(\text { days decade }{ }^{-1}\right)\end{array}$ & $-0.03(-0.2)$ & $-0.6(-1.9) * *$ & $-0.02(-0.09)$ & $-1.67(-3.4)^{* *}$ \\
\hline DDPDE(days decade ${ }^{-1}$ ) & $2.6(5.3)^{* *}$ & $-1.1(-0.8)^{* *}$ & $1.9(2.7)^{*}$ & $1.2(0.7)$ \\
\hline
\end{tabular}

*Significant at $p=0.1 ; *$ significant at $p=0.05$; unit in parentheses are $\%$ decade $^{-1}$.

winter half-year. With the 1-mm threshold, for the summer, 30 sites exhibit positive trends ( 9 sites are significant at $p=0.05$ or 14 sites at $p=0.10$ ) and only 4 sites display negative, non-significant trends. For the winter, only 8 sites exhibit positive trends (all non-significant) while 26 sites display negative trends ( 2 sites are significant at $p=0.05$ or 4 sites at $p=0.10)$. The summer trends in DDPDE correspond well with the trends in the frequency of prolonged dry episodes, while the winter DDPDE trends correspond more with the trends in the mean length of prolonged dry episodes. For the threshold of $2 \mathrm{~mm}$ during the summer half-year, the trend in DDPDE repeats the pattern for the threshold of $1 \mathrm{~mm}$, with most of sites showing positive trends. During the winter half-year, though, the pattern for the 2-mm threshold differs, with relatively more stations showing positive trends. Although most of the stations' trends do not reach a statistically significant level, the high spatial coherence in the trend of DDPDE during the winter and summer half-years is suggestive of an influence of large-scale climate forcing.

Dry episodes are related to temporal characteristics of precipitation: an individual prolonged dry episode indicates a temporal aberration related to the timing and effectiveness of precipitation (Lei and Duan, 2011). As Northeast China is located in the East Asia monsoon region, the moisture available locally for precipitation depends a great deal on the transport of moisture by the atmosphere from other regions during the summer half-year. Over the past few decades, the changing pattern of summer precipitation in China has been characterized as 'southern flood and northern drought'. The East Asian summer monsoon has significantly weakened, and the decline in northward moisture transport is regarded as the main reason of decrease of precipitation in North China (Yu et al., 2004; Ding et al., 2008). The weakening of the summer monsoon causes summer rainfall to start later, end sooner, and decrease in total amount (Li and Liu, 2006). The widespread increase in DDPDE indicates dryer conditions in Northeast China during the summer half-year; these correspond with large-scale atmospheric circulation changes. During the same period, the decreasing trend in soil moisture during the summer half-year in North China
(Zuo and Zhang, 2009; Zhu et al., 2012) further confirms the DDPDE trend.

The East Asian winter monsoon is controlled by cold, dry air, with very little atmospheric moisture content compared with summer (Jhun and Lee, 2004). The intensity of the winter monsoon generally shows a strong negative correlation with air temperature and precipitation over the eastern regions of China (Shi, 1996). Precipitation during the winter half-year over Northeast China generally shows an increasing trend (Liu et al., 2005). The winter monsoon has weakened in China over the past several decades, contributing to increased precipitation in Northeast China (Peterson et al., 2001; Wang et al., 2004). The increase of precipitation and decrease in the number of dry days influence short-term dry conditions in Northeast China by producing more but shorter prolonged dry episodes.

Comparing our results with studies from other regions highlights the effects of the water conditions in the climatic system affecting Northeast China. In the American Southwest, for example, both the summer and winter trends in the number of dry days are moving in the same direction, with differences only in the magnitude of change (McCabe et al., 2010). This contrasts with the opposing summer and winter trends in Northeast China. But the two regions do share similar trends for some other indicators of dry episodes; for example, in both places, the decrease in winter dry days is generally inducing a shortening of prolonged dry episodes.

\subsection{Regional average trends of prolonged dry episodes}

Drought indicators for each station reflect a mix of local, regional, and global-scale climate forcings. The contribution from any particular forcing to the variance in each drought indicator is non-stationary through time. Increasing the spatial scale of analysis can reduce the unexplainable variability (or 'noise') and enhance the signal-to-noise ratio (Nicholls, 2001). Here we apply spatial averaging of station data to reduce noise and enhance the signal in the drought indicator time series.

Table 2 presents the regional average trend for each indicator by summer and winter half-years. Trends are given both in absolute terms and in percentage terms. Taking the 
region as a whole, for the threshold of $1 \mathrm{~mm}$, the decline in summer precipitation is accompanied by an increase in dry days; there is also a significant increase in the number of prolonged dry episodes in the summer half-year. The patterns are similar, but of smaller magnitude, for the 2-mm threshold. The opposite pattern emerges in the winter half-year, with increased precipitation, a small but significant decrease in dry days and a significant decrease in dry event length at the 1-mm threshold. At the 2-mm threshold, the decrease in dry days is only significant at the $10 \%$ level. While there is a significant increase in the number of prolonged dry episodes and a significant decrease in dry event length, for the threshold of $2 \mathrm{~mm}_{\text {day }}{ }^{-1}$, the trend in DDPDE is not statistically significant. This implies that, for the threshold of $2 \mathrm{~mm}$, there are no significant long-term changes in the DDPDE even though the frequency and mean length of long dry spells have changed significantly.

Some indicators do not show a significant change at the regional level, consistent with the mix of positive and negative, mostly small and non-significant trends at individual stations. However, the trends in the other indicators of prolonged dry episodes are spatially coherent. Although most of these trends do not reach statistical significance for individual stations, the regional average does change significantly. The regional trends were obtained from average indices series calculated as the arithmetic average of the seasonal indices values at all 34 stations. Regional averaging reduces the variance of the resulting time series (as the 34 stations' indices time series are not correlated with $r=1$ ) that also plays a role in significance tests. The higher statistical significance for the regional average trends presumably reflects the reduction of noise variance associated with the averaging process.

Overall, DDPDE increases rapidly in the summer half-year. This indicates that Northeast China has seen a shift to dryer conditions during the summer half-year over the past several decades. The regional trend shows that the change in DDPDE in the summer half-year is mainly related to the changes in the frequency of prolonged dry episodes, whether the1- or 2-mm threshold is applied. The change in DDPDE in the winter half-year is mainly affected by changes in the mean length of prolonged dry episodes for the threshold of $1 \mathrm{~mm}$. For the threshold of $2 \mathrm{~mm}$, the frequency and mean length of long dry spells change significantly but in opposite directions, producing no obvious changes in DDPDE. Comparing the percentage changes in the number of dry days and DDPDE (see Table 2, shown in parentheses), we find that the number of dry days changes at a much lower rate than DDPDE during the summer half-year. The same is true for the winter half-year, but the difference is not as large. This implies that DDPDE can change greatly even through the number of dry days does not.

Figure 12 plots the regional average number of dry days and the frequency of prolonged dry episodes for each year in our study period. These two indicators covary closely in the summer half-year but are out of phase for the winter half-year through most of the study period, excepting the years 1987-1993. During the summer half-year, reduction in precipitation frequency can lead to more frequent prolonged dry episodes. The number of dry days and the frequency of prolonged dry episode are inversely correlated during the winter half-year: fewer dry days correspond with more prolonged dry episodes. The frequency of prolonged dry episodes reaches the highest levels from the 1990s onward in both summer and winter.

Figure 13 plots the time series of the regional average mean length of prolonged dry episodes and DDPDE. The patterns are similar for the 1- and 2-mm thresholds. Summer measurements show shorter prolonged dry episodes during the 1970 s and 1980s, followed by an increasing trend from the 1990s. Summer DDPDE changes differently than the mean length of prolonged dry episodes during the period 1965-1980 and in the mid-1990s, but these two indicators follows the same general pattern in other periods. Comparing Figures 12(a) and 13(a), we note that, for 1965-1980 and around the mid-1990s, the mean length and frequency of prolonged dry episodes move in opposite directions, while DDPDE follows the change in frequency. We interpret this to mean that, during these two periods, changes in the frequency of prolonged dry episodes made the largest contribution to DDPDE. Winter patterns for indicators of mean length of prolonged dry episodes and DDPDE show fluctuations around the period means, largely in phase with each other, with an overall decrease reaching the lowest point around 2006-2007.

In order to compare with the regional results, for each site we calculated the changes in DDPDE that could be attributed to changes in prolonged dry episode frequency versus changes in prolonged dry episode length (Table 3). For the summer half-year, change in DDPDE can mainly be attributed to changes in the frequency of prolonged dry episodes at most sites for both thresholds. During the winter half-year, changes in the length of prolonged dry episodes contributed most to the changes in DDPDE at most sites for the threshold of $1 \mathrm{~mm}$, but for the threshold of $2 \mathrm{~mm}$ there were more sites where changes in the frequency of prolonged dry episodes contributed most to the changes in DDPDE.

We also calculated the correlation between the number of dry days and the frequency and mean length of prolonged dry episodes for each site (Table 4). Change in the number and temporal distribution of dry days is the basic reason for the changes in prolonged dry episodes. For the threshold of $1 \mathrm{~mm}$ during the summer half-year, 32 of the 34 sites show significant correlations between the number of dry days and the number of prolonged dry episodes, while only 4 sites show significant correlations between the number of dry days and the mean length of prolonged dry episodes. By contrast, during the winter half-year, 29 of the 34 sites show significant correlations between number of dry days and the mean length of prolonged dry episode, while only 9 sites show significant correlations between number of dry days and number of prolonged dry episodes. This implies that for the 1-mm threshold, changes in the number of dry days have different effects in summer and winter: inducing 

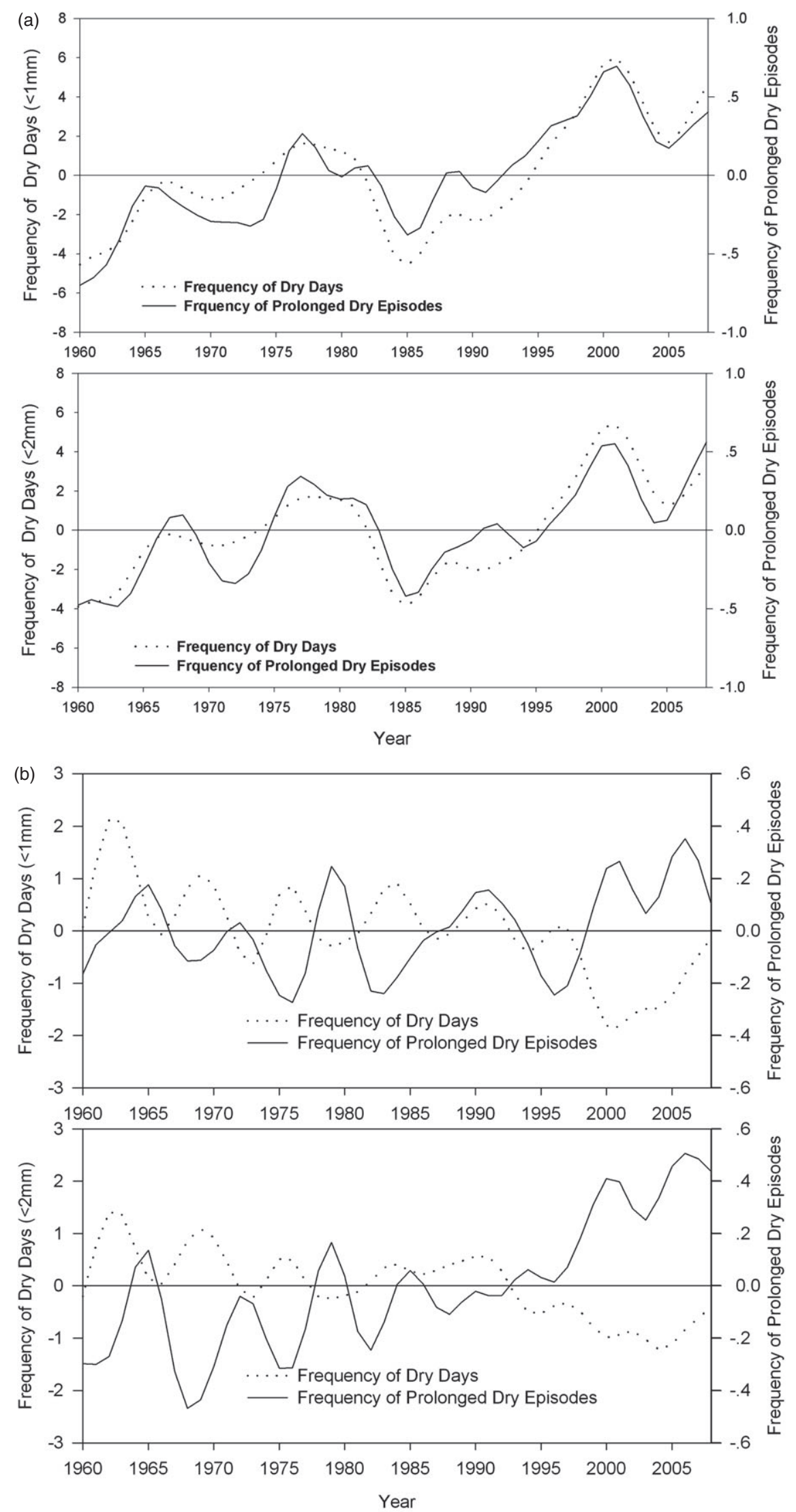

Figure 12. Temporal changes of regional average frequency of dry days and frequency of prolonged dry episodes: anomalies (from the 1960-2008 mean) in (a) summer and (b) winter half-years (values smoothed with a nine-point binomial filter with reflected ends). 

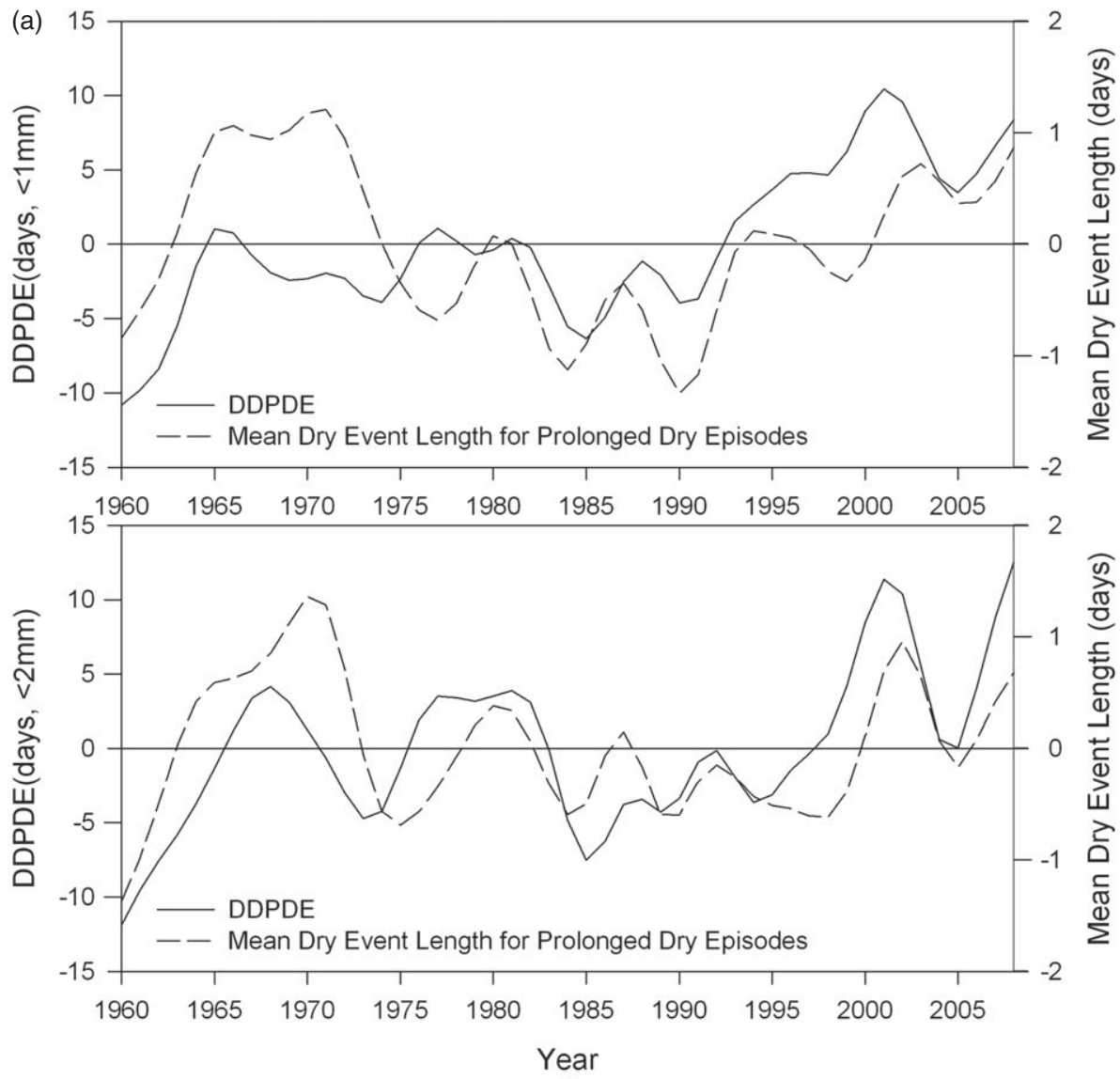

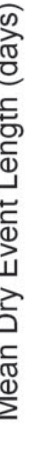

(b)
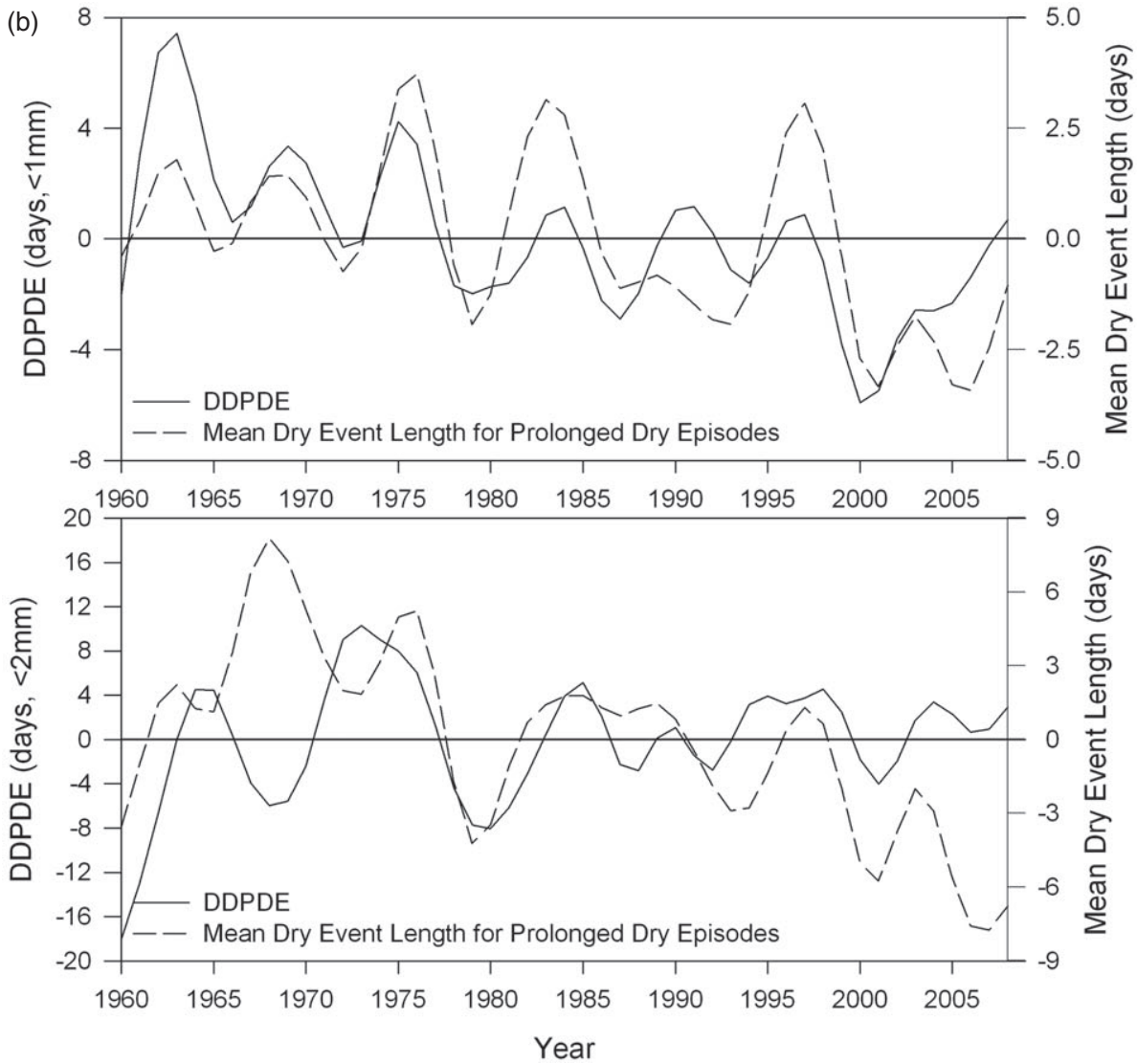

Figure 13. Temporal changes of regional average DDPDE and mean dry event length for prolonged dry episodes: anomalies (from the 1960-2008 mean) in (a) summer and (b) winter half-years (values smoothed with a nine-point binomial filter with reflected ends). 
Table 3. Number of sites where DDPDE trends are related to changes in frequency or length of prolonged dry episodes.

\begin{tabular}{lccccc}
\hline & \multicolumn{2}{c}{$<1 \mathrm{~mm} \mathrm{day}^{-1}$} & & \multicolumn{2}{c}{$<2 \mathrm{~mm}^{-1}$ day $^{-1}$} \\
\cline { 2 - 3 } & Summer half-year & Winter half-year & & Summer half-year & Winter half-year \\
\hline Prolonged dry episode frequency & 31 & 12 & 21 & 19 \\
Prolonged dry episode length & 3 & 22 & & 13 & 15 \\
\hline
\end{tabular}

Table 4. Number of sites with significant correlation coefficient (at 95\% confidence level) between indicators.

\begin{tabular}{|c|c|c|c|c|}
\hline & \multicolumn{2}{|c|}{$<1 \mathrm{~mm} \mathrm{day}^{-1}$} & \multicolumn{2}{|c|}{$<2 \mathrm{~mm} \mathrm{day}^{-1}$} \\
\hline & Summer half-year & Winter half-year & Summer half-year & Winter half-year \\
\hline $\begin{array}{l}\text { Number of dry days versus Number of } \\
\text { prolonged dry episode }\end{array}$ & 32 & 9 & 29 & 22 \\
\hline $\begin{array}{l}\text { Number of dry days versus Mean dry event } \\
\text { length for prolonged dry episodes }\end{array}$ & 4 & 29 & 10 & 31 \\
\hline
\end{tabular}

changes in the number of prolonged dry episode during the summer half-year but inducing changes in the mean dry event length during the winter half-year.

For the threshold of $2 \mathrm{~mm}$ during the summer half-year, 29 of the 34 sites show significant correlations between the number of dry days and number of prolonged dry episodes, and 10 sites show significant correlations between the number of dry days and the mean length of prolonged dry episodes. However, during the winter half-year, 31 of the 34 sites show significant correlations between the number of dry days and the mean length of prolonged dry episode, and 22 sites show significant correlations between the number of dry days and the number of prolonged dry episodes. These implies that, for the 2-mm threshold, changes in the number of dry days are inducing changes in the number of prolonged dry episode during the summer half-year but inducing changes in both the number of prolonged dry episode and mean dry event length during the winter half-year. During the winter half-year, we can see stronger effect for the changes in number of dry days on the frequency of prolonged dry episode for the threshold of $2 \mathrm{~mm}$ (during winter half-year, for most sites, there are not many days with precipitation above $2 \mathrm{~mm}$ ). Since DDPDE reflects the combined effect of the number and length of prolonged dry episodes, this means that there are seasonal differences in the cause of changes in DDPDE. This further confirms the regional average result.

This finding highlights the importance of differentiating among types of changes in the character of prolonged dry episodes, whether their frequency, their mean length, or the interaction of these two in DDPDE. This may help to explain the differing conclusions drawn by McCabe et al. (2010) and Groisman and Knight (2008) concerning trends of prolonged dry episodes in the southwestern United States. McCabe et al. (2010) reported on the mean length of prolonged dry episodes, while Groisman and Knight (2008) reported on the DDPDE indicator. As we have found for Northeast China, changes in either the frequency or the mean length of prolonged dry episodes can cause changes in DDPDE; and trends in DDPDE may not track the change in mean length of prolonged dry episode for certain periods. If this holds true for other regions, then the use of different indicators to represent prolonged dry episodes may be one reason for the differing conclusions of McCabe et al. (2010) and Groisman and Knight (2008) for the southwestern United States.

\section{Conclusions}

Analysing dry days and prolonged dry episodes during the winter and summer half-years in Northeast China for the period of 1960-2008, we found the following:

- Dry days ( $<1.0$ and $<2 \mathrm{~mm} \mathrm{day}^{-1}$ ) are more prevalent in the western part of the region and in the winter half-year.

- Prolonged dry events ( $\geq 10$ days) are longer and more frequent in the western part of the region in the summer; in the winter, they are much longer in the western part and more frequent in the eastern part.

- DDPDE is higher in the western part of the region and in the winter half-year.

For the Northeast China region as a whole, we find that:

- The number of dry days is trending upward in summer and downward in winter.

- The frequency of prolonged dry episodes shows an increasing trend during the summer half-year, while the mean length of prolonged dry episodes shows a decreasing trend during the winter half-year.

- DDPDE is increasing in summer; the increased frequency of dry spells has the greatest effect.

These findings indicate that either the frequency or the mean length of prolonged dry episodes, alone, cannot fully describe the short-term dry conditions of an area. Multiple characteristics of dry spells, including frequency, length, and the number of DDPDE should be considered. DDPDE is a function of both the frequency and length of dry episodes, but may be more influenced by one or the other characteristics of dry spells, depending on the season or region. 


\section{Acknowledgements}

This research was partially supported by National Science and Technology Support Program (2011BAD32B05) and the Beijing Forestry University Innovation Program Project (BLRW200939); as well as by the 'Climate change influence on dry days and dry event in China' research grant, a part of a Forest and Wetland Ecosystem Protection Subproject of the Beijing Forestry University 985 Platform Project. The Chinese Academy of Sciences and Rutgers University provided computational facilities for data analysis.

\section{References}

Adam JC, Lettenmaier DP. 2003. Adjustment of global gridded precipitation for systematic bias. J. Geophys. Res. 108(D9): 4257, DOI 10.1029/2002JD002499.

Aviad Y, Kutiel H, Lavee H. 2009. Variation of dry days since last rain (DDSLR) as a measure of dryness along a Mediterranean-Arid transect. J. Arid Environ. 73: 658-665.

Balling RC, Goodrich GB. 2010. Increasing drought in the American Southwest? A continental perspective using a spatial analytical evaluation of recent trends. Phys. Geogr. 31: 293-306.

Cook GD, Heerdegen RG. 2001. Spatial variation in the duration of the rainy season in monsoonal Australia. Int. J. Climatol. 21: 1723-1732.

Déque M. 2007. Frequency of precipitation and temperature extremes over France in an anthropogenic scenario: model results and statistical correction according to observed values. Global Planet. Change 57: 16-26.

Diffenbaugh NS, Pal JS, Trapp RJ, Giorgi F. 2005. Fine-scale processes regulate the response of extreme events to global climate change. Proc. Natl. Acad. Sci. 102: 15774-8.

Ding YH, Wang ZY, Sun Y. 2008. Inter-decadal variation of the summer precipitation in East China and its association with decreasing Asian summer monsoon. Part I: Observed evidences. Int. J. Climatol. 28(9) 1139-1161.

Frich P, Alexander LV, Della Marta P, Gleason B, Haylock M, Klein Tank AMG, Peterson T. 2002. Observed coherent changes in climatic extremes during the second half of the twentieth century. Clim. Res. 19: $193-212$

Gillette HP. 1950. A creeping drought under way. Water Sewage Works 97: $104-105$

Glantz MH, Katz R. 1977. When is a drought a drought. Nature 267: 192-193.

Gong DY, Shi P, Wang J. 2004. Daily precipitation changes in the semi-arid region over northern China. J. Arid Environ. 59: $771-784$

Gong DY, Wang JA, Han H. 2005. Trends of summer dry spells in China during the late twentieth century. Meteorol. Atmos. Phys. 88(3-4): 203-214.

Griffiths ML, Bradley RS. 2007. Variations of twentieth-century temperature and precipitation extreme indicators in the Northeast United States. J. Clim. 20: 5401-5417.

Groisman P, Knight R. 2008. Prolonged dry episodes over the conterminous United States: new tendencies emerging during the last 40 years. J. Clim. 21: 1850-1862.

Groisman PY, Knight RW, Easterling DR, Karl TR, Hegerl GC, Razuvaev VN. 2005. Trends in intense precipitation in the climate record. J. Clim. 18: 1326-1350.

Haylock MR, Cawley GC, Harpham C, Wilby RL, Goodess CM. 2006. Downscaling heavy precipitation over the UK: a comparison of dynamical and statistical methods and their future scenarios. Int. J. Climatol. 26: 1397-1415.

Huth R, Kysely J, Pokorna I. 2000. A GCM simulation of heat waves, dry spells, and their relationships to circulation. Clim. Change 46 : 29-60.

Jhun J, Lee E. 2004. A new east Asian winter monsoon index and associated characteristics of the winter monsoon. J. Clim. 17: $711-726$

Karl TR, Knight RW. 1998. Secular trends of precipitation amount, frequency, and intensity in the USA. Bull. Am. Meteorol. Soc. 79: $231-241$.
Karl TR, Meehl GA, Miller CD, Hassol SJ, Waple AM, Murray WL. 2008. Weather and climate extremes in a changing climate; regions of focus: North America, Hawaii, Caribbean, and U.S. Pacific Islands. Synthesis and assessment Product 3.3. Report by the U. S. Climate Change Science Program and the Subcommittee on Global Change Research. Washington, DC, 164

Kruger AC. 2006. Observed trends in daily precipitation indices in South Africa: 1910-2004. Int. J. Climatol. 26: 2275-2285.

Kutiel H. 1985. The multimodality of the rainfall course in Israel, as reflected by the distribution of dry spells. Arch. Meteorol. Geophys. Bioclimatol. 36B: 15-27.

Lei Y, Duan A. 2011. Prolonged dry episodes and drought over China. Int. J. Climatol. 31: 1831-1840.

Li JR, Liu BH. 2006. The change character of monsoon rainband over Heilongjiang province for the past 40 years. J. For. Res. 17(1): 71-74. Liu BH, Xu M, Henderson M. 2005. Observed trends of precipitation amount, frequency, and intensity in China, 1960-2000. J. Geophys. Res. 110: D08103, DOI: 10.1029/2004JD004864.

Liu BH, Henderson M, Xu M. 2008a. Spatiotemporal change in China's frost days and frost-free season, 1955-2000. J. Geophys. Res. 113: D12104, DOI: 10.1029/2007JD009259.

Liu LH, Zhai PM, Zheng ZG. 2008b. Variations in longest consecutive dry days in warm half-year over Northern China. Acta Meteorologica Sinica 66(3): 474-477 (in Chinese).

Liu BH, Henderson M, Zhang YD, Xu M. 2010. Spatiotemporal change in China's climatic growing season: 1955-2000. Clim. Change 99: 93-118, DOI: 10.1007/s10584-009-9662-7.

Liu BH, Henderson M, Xu M, Zhang Y. 2011a. Observed changes in precipitation on the wettest days of the year in China, 1960-2000. Int. J. Climatol. 31(4): 487-503.

Liu BH, Xu M, Henderson M. 2011b. Where have all the showers gone? Regional declines in the occurrences of light precipitation events in China, 1960-2000. Int. J. Climatol. 31(8): 1177-1191.

Martin-Vide J, Gomez L. 1999. Regionalization of Peninsular Spain based on the length of dry spells. Int. J. Climatol. 19: 537-555.

Mathugama SC, Peiris TSG. 2011. Critical evaluation of dry spell research. Int. Basic Appl. Sci. 11: 153-160.

McCabe GJ, Legates DR, Lins HF. 2010. Variability and trends in dry day frequency and dry event length in the southwestern United States. J. Geophys. Res. 115: D07108, DOI: 10.1029/2009JD012866.

Michaels PJ, Knappenberger PC, Frauenfeld OW, Davis RE. 2004. Trends in precipitation on the wettest days of the year across the contiguous USA. Int. J. Climatol. 24: 1873-1882.

Moberg A, Jones PD. 2005. Trends in indices for extremes in daily temperature and precipitation in central and western Europe, 1901-99. Int. J. Climatol. 25: 1149-1171.

Nastos PT, Zerefos CS. 2009. Spatial and temporal variability of consecutive dry and wet days in Greece. Atmos. Res. 94: 616-628.

New M, Hewitson B, Stephenson DB, Tsiga A, Kruger A, Manhique A, Gomez B, Coelho ASC, Masisi DN, Kululanga E, Mbambalala E, Adesina F, Saleh H, Kanyanga J, Adosi J, Bulane L, Fortunata L, Mdoka ML, Lajoie R. 2006. Evidence of trends in daily climate extremes over southern and West Africa. J. Geophys. Res. 111: D14102, DOI: 10.1029/2005JD006289.

Nicholls N. 2001. The insignificance of significance testing. Bull. Am. Meteorol. Soc. 82: 981-986.

Perzyna G. 1994. Spatial and temporal characteristics of maximum dry Spells in southern Norway. Int. J. Climatol. 14: 895-909.

Peterson TC, Folland C, Gruza G, Hogg W, Mokssit A, Plummer N. 2001. Report on the activities of the Working Group on Climate Change Detection and Related Rapporteurs 1998-2001. Report WCDMP-47, WMO-TD 1071, World Meteorological Organization, Geneva, Switzerland.

Piao S, Yin L, Wang X, Ciais P, Peng S, Shen Z, Seneviratne SI. 2009. Summer soil moisture regulated by precipitation frequency in China. Environ. Res. Lett. 4: 044012, DOI: 10.1088/1748-9326/4/4/044012.

Qian W, Lin X. 2005. Regional trends in recent precipitation indices in China. Meteorol. Atmos. Phys. 90: 193-207.

Qian W, Fu J, Yan Z. 2007. Decrease of light rain events in summer associated with a warming environment in China during 1961-2005. Geophys. Res. Lett. 34: L11705, DOI: 10.1029/2007GL029631.

Reiser H, Kutiel H. 2010. Rainfall uncertainty in the Mediterranean: dryness distribution. Theor. Appl. Climatol. 100: 123-135.

Ren ZH, Wang GL, Zou FL, Zhang HZ. 2003. The research of precipitation measurement errors in China. Acta Meteorologica Sinica 61(5): 621-627 (in Chinese).

Salinger MJ, Griffiths GM. 2001. Trends in New Zealand daily temperature and rainfall extremes. Int. J. Climatol. 21(12): 1437-1452. 
Schmidli J, Frei C. 2005. Trends of heavy precipitation and wet and dry spells in Switzerland during the 20th century. Int. J. Climatol. 25: 753-771, DOI: 10.1002 /joc. 1179.

She D, Xia J. 2012. The spatial and temporal analysis of dry spells in the Yellow River basin, China. Stochastic Environ. Res. Risk Assess. 27: 29-42.

Shi N. 1996. Features of the east Asian winter monsoon intensity on multiple time scale in recent 40 years and their relation to climate. $Q$. J. Appl. Meteorol. 7(2): 175-182.

Solomon S, Qin D, Manning M, Chen Z, Marquis M, Averyt K, Tignor M, Miller H (eds). 2007. Climate Change 2007: The Physical Science Basis. Contribution of Working Group 1 to the Fourth Assessment Report of the Intergovernmental Panel on Climate Change. Cambridge University Press: Cambridge, UK and New York, NY; 996.

Suppiah R, Hennessy KJ. 1998. Trends in total rainfall, heavy rain events and number of dry days in Australia, 1910-1990. Int. J. Climatol. 10: $1141-64$.

Trenberth KE. 2011. Changes in precipitation with climate change. Clim. Res. 47: 123-138.
Wang Z, Ding Y, He J, Yu J. 2004. An updating analysis of the climate change in China in recent 50 years. Acta Meteorologica Sinica 62(2): 228-236.

Wang Y, Shi N, Gu J, Feng G, Zhang L. 2006. Climatic variations of wet days in China. Chin. J. Atmos. Sci. 30: 162-170 (in Chinese).

Wilhite DA, Glantz MH. 1985. Understanding the drought phenomenon: the role of definitions. Water Int. 10(3): 111-120.

Yu R, Wang B, Zhou T. 2004. Tropospheric cooling and summer monsoon weakening trend over East Asia. Geophy. Res. Lett. 31: L22212, DOI: 10.1029/2004GL021270.

Zhai P, Sun A, Ren F, Liu X, Gao B, Zhang Q. 1999. Changes of climate extremes in China. Clim. Change 42: 203-218.

Zhu HX, Gong LJ, Qu HH, Lu JJ, Wang LL, Li BC, Ji YH, Yan P, Wang QJ, Jiang LX, Wang P. 2012. The evolution of summer soil moisture from 1981 to 2010 in Heilongjiang province. J. Meteorol. Environ. 28(5): 34-39 (in Chinese).

Zuo ZY, Zhang RH. 2009. Temporal and spatial features of the soil moisture in boreal spring in eastern China. Sci. Chin. Ser. D: Earth Sci. 52(2): 269-278. 